REAL EXCHANGE RATE OVERSHOOMING AND THE OUTPUT COST OF BRINGING DOWN INFLATION

Willem H. Buiter

Marcus Miller

Working Paper No. 749

NATIONAL BUREAU OF ECONOMIC RESEARCH 1050 Massachusetts Avenue

Cambridge MA 02138

September 1981

Paper presented at the International Seminar in Macroeconomics, organized jointly by the Maison des Sciences de l'Homme and the National Bureau of Economic Research in Paris, June 18, 1981. (Revised August 1981). The authors have benefitted from discussions with Avinash Dixit. Financial support from the Leverhulme Trust is gratefully acknowledged. The research reported here is part of the NBER's research program in International Studies. Any opinions expressed are those of the authors and not those of the National Bureau of Economic Research. 


\title{
REAL EXCHANGE RATE OVERSHOOTING AND THE OUTPUT COST OF BRINGING DOWN INFLATION
}

\author{
$\underline{\text { Abstract }}$ \\ Implementing a 'gradualist' policy of monetary contraction, in an \\ open economy with a freely floating exchange rate but with nominal inertia \\ in domestic labor costs, can lead to prompt and substantial changes in \\ the nominal and real exchange rate. One of the virtues claimed for such \\ exchange rate 'overshooting', however, is its immediate effect on the \\ price level and so on domestic wage and price inflation. \\ In this paper we show that, in a model which is 'super-neutral' and \\ has nominal inertia in both the level of labor costs and their trend or \\ core rate of growth, this early overshooting of the exchange rate does \\ not succeed in cutting the output costs of reducing steady-state inflation. \\ Those output and unemployment costs which are initially avoided by over- \\ valuing the currency have to be paid later when this overvaluation is \\ corrected. Relative to other policies which achieve the same effect on \\ steady-state inflation, exchange rate overshooting brings inflation down \\ more quickly. \\ Willem H. Buiter \\ Department of Economics \\ University of Bristol \\ Alfred Marshall Building \\ 48 Berkeley Square \\ Bristol B58 IHY \\ Te1. 0272-24161 \\ Marcus M. Miller \\ Department of Economics \\ University of Warwick \\ Coventry CV4 7AL \\ Te1. 020324011
}




\section{Introduction}

The proposition that under a floating exchange rate regime restrictive monetary policy can lead to substantial "overshooting" of the nominal and real exchange rate is now accepted fairly widely. The fundamental reason is the presence of nominal stickiness or inertia in domestic factor and product markets combined with a freely flexible nominal exchange rate. Current and anticipated future monetary policy actions are reflected immediately in the nominal exchange rate, set as it is in a forward-looking efficient auction market, while they are reflected only gradually and with a lag in domestic nominal labour costs and/or goods prices. Nominal appreciation of the currency therefore amounts to real appreciation - a loss of competitiveness. Since in most of the simple analytical models used to analyse the overshooting propositions there is no long-run effect of monetary policy on the real exchange rate, any short-run real appreciation implies an overshooting of the long-run equilibrium. The transitory (but potentially quite persistent) loss of competitiveness is associated with a decline in output below its capacity level. This excess capacity is one of the channels through which restrictive monetary policy brings down the rate of domestic cost and price inflation.

One of the virtues claimed for the sharp initial appreciation of the nominal and real exchange rate in response to a previously unanticipated tightening of the stance of monetary policy is its immediate effect on the domestic price level. The domestic currency prices of those internationally traded goods whose foreign currency prices can be treated as exogenous will decline by the same proportion as the increase in the value of the domestic currency. To a greater or lesser extent the same holds even for those internationally traded goods where the home country is large in relation to the world market. Both through its effect on the 
prices of internationally traded final goods and through its effect on the price of imported raw materials and intermediate inputs, a sudden step appreciation of the exchange rate will immediately bring down the domestic price level. In this paper we shall argue that the effect of such exchange the cost of reducing rate jumps is merely to redistributefinflation over time: early gains have to be "handed back" later as the equilibrium level of competitiveness is restored. Crucial to this argument is the assumption of stickiness of by our assumption of a predetermined nominal money wage and some nominal domestic cost component. In our model this is built in/through our specification of the behaviour of the "core" or underlying rate of inflation, $\pi$, the augmentation term in the wage Phillips curve. Subject to one quite significant qualification, the core rate of inflation is viewed as predetermined with its behaviour over time governed by a first order partial adjustment mechanism. It can be thought of as an adaptive expectations mechanism for the labour market although we do not favour that interpretation. In our view the core rate of inflation, which is a distributed lag on past rates of inflation, stands for all the factors in the economy that give inertia to built-in trends in wages and prices. Also, while the level of the money wage is always treated as predetermined, $\pi$, while determined by a "backward-looking" process,can make discrete jumps at a point in time. This will happen whenever there is a discrete jump in the general price level. In our model this can occur either if the exchange rate jumps or if there is a change in indirect taxes. Since the exchange rate is a forward-looking price which responds to "news" about current and future shocks, the underlying rate of inflation indirectly and to a limited extent also responds to such shocks.

To put the present paper in perspective it is useful to relate our current approach to that of an earlier paper (Buiter and Miller [1981]). This is done in Section 2 where a simple model of real exchange rate 
overshooting is discussed. Section 3 contains some modifications of the simple model. It is here that we discuss the implications of assuming flexibility of domestic nominal wage costs. While we do not believe that such a "neo-classical" specification is appropriate for the analysis of an advanced industrial economy like the U.K., the discussion of this case helps bring out the crucial nature of the assumption of nominal inertia in the behaviour of domestic costs. Section 4 analyzes in some detail the behaviour of the model with sluggish "core" inflation.

2. $\Lambda$ Simple Model of keal Lxchange Rate Overshooting

A slightly simplified version of the model in Buiter and Miller [1981] is given in equations (1) - (5). All variables except for $r, r_{d}, r^{*}$, $\pi, \theta$ and $\tau$ are in logs.
(1)

$$
m-p-\theta=k y-\lambda\left(r-r_{d}\right)
$$$$
k, \lambda>0
$$

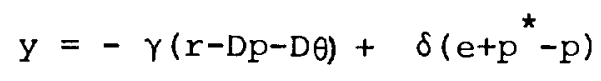$$
\gamma, \delta>0
$$
(3) $\quad \mathrm{Dp}=\phi Y+\pi$ $\phi>0$
(4) $\pi=D^{+} m$
(5) $\quad$ De $=r-r^{\star}-\tau$

The notation is as follows

m : nominal money stock (exogenous)

p : domestic price level "at factor cost" i.e. excluding indirect taxes (predetermined)

$\mathrm{p}^{\star}$ : foreign price level (exogenous)

y : real output (endogenous)

$r$ : domestic nominal interest rate on non-money assets (endogenous)

$r_{d}$ : nominal interest rate paid on domestic money (exogenous) 
$r^{\star}$ : foreign nominal interest rate paid on non-money assets (exogenous)

$\theta$ : rate of indirect tax (exogenous)

e : exchange rate (domestic currency price of foreign currency) (endogenous)

$\pi$ : trend or core rate of inflation (endogenous)

$\tau$ : rate of tax on capital inflows or subsidy on outflows (exogenous)

$D$ : differential operator, i.e. $D x(t) \equiv \frac{d}{d t} x(t)$

$\mathrm{D}^{+}$: right-hand side differential operator, i.e. $\mathrm{D}^{+} \mathrm{x}(\mathrm{t})=\lim _{\mathrm{T} \rightarrow \mathrm{t}}\left(\frac{\mathrm{x}(\mathrm{T})-\mathrm{x}(\mathrm{t})}{\mathrm{T}-\mathrm{t}}\right)$ $T>t$

Equation (1) is the LM curve: $m$ denotes a fairly wide monetary aggregate such as $£$ M3 which consists, to a significant extent (50-60\%), of interestbearing deposits. We therefore measure the opportunity cost of holding money by the interest differential between the loan rate, $r$, and the own rate on time deposits $\left(r_{d}\right)$. Equation (2) is the Is curve. Demand for domestic output depends on the short real interest rate and on the relative price of foreign and domestic goods. A fiscal policy variable could be added without difficulty. Preferable alternative specifications include replacing the short real interest rate by the long real interest rate and modelling output as predetermined, with its rate of change depending on the excess of ex ante effective demand over the level of real output. This would preclude the unrealistic immediate jumps in real output in response to e.g. a loss of competitiveness which are a feature of the current model. Ihe country is small in the world market for its importables so that it takes $P^{\star}$ as given. It is large in the world market for its exportables. No explicit distinction is made between traded and non-traded goods. Equation (3) is the augmented Phillips curve. By choice of units (the logarithm of) capacity output is set equal to zero. The augmentation term $\pi$ is identified, in (4), with the right-hand side time-derivative of the money supply. Thus even if $m$ were to make a discrete jump, the price 
level would not jump. This is one way of imposing the crucial property of nominal inertia, stickiness or sluggishness. Equation (5) reflects the assumption of perfect capital mobility and perfect substitutability between domestic and foreign bonds. Risk-neutral speculators equate the uncovered interest differential in favour of the domestic country, net of any tax on capital imports, to the expected rate of depreciation of the domestic currency. The country is small in the world financial markets and $r^{*}$ is treated as given. The assumption of rational expectations, employed in Dornbusch [1976], Liviatan/and Buiter and Miller [1981] is equivalent to perfect foresight in our deterministic model. It is used in equations (2) and (5). For simplicity the foreign price level, $\mathrm{p}^{*}$, is assumed to be constant. Choice of units sets it equal to zero, so competitiveness is measured by e-p.

The own rate of interest on money is assumed exogenous. In a competitive banking system with a binding required reserve ratio $h$, $(0<h<1$ ) on all bank deposits, the loan rate $r$ and the deposit rate $r_{\mathrm{d}}$ are linked by: $r_{\mathrm{d}}=(1-\mathrm{h}) \mathrm{r}(\mathrm{TD}+\mathrm{DD}) \mathrm{TD}^{-1}$.

TD is the volume of interest-bearing time deposits and DD the volume of non-interest-bearing demand deposits. If demand deposits are only a small fraction of the total, then $r_{d} \simeq(1-h) r$. This can be used to eliminate $r_{d}$ from the model. The main consequence is to reduce the interest sensitivity of money demand. We prefer treating $r_{d}$ as exogenous so that discretionary changes in $r_{d}$ can be used to describe policy actions to alter the degree of competitiveness of the banking system. The dynamics of the system is conveniently summarized in terms of the two state variables $\ell$ and $c$ :

(6a) $\quad l \equiv m-p$

(6b) $\quad c \equiv e-p$ 
Real liquidity, $\ell$, is a backward-looking or predetermined variable. It only makes discrete jumps when the policy instrument $m$ changes discontinuously. Real competitiveness $c$ is a forward-looking or jump variable. It jumps whenever e jumps. The state-space representation of the model of equations (1) - (6) is:

$$
\left[\begin{array}{ll}
D & l \\
D & C
\end{array}\right]=\frac{1}{\gamma(\phi \lambda-k)-\lambda}\left[\begin{array}{ll}
\phi \gamma & \phi \lambda \delta \\
1 & \delta(\phi \lambda-k)
\end{array}\right]\left[\begin{array}{l}
l \\
C
\end{array}\right]
$$

$$
+\frac{1}{\gamma(\phi \lambda-k)-\lambda}\left[\begin{array}{cccc}
\phi \lambda \gamma & 0 & -\phi \gamma & -\phi \gamma \lambda \\
\lambda & -\gamma(\phi \lambda-k)+\lambda & -1 & -\lambda
\end{array}\right]\left[\begin{array}{c}
D m \\
r^{*}+\tau \\
0 \\
r_{d}
\end{array}\right]
$$

A necessary and sufficient condition for the stationary equilibrium of this model to be a saddlepoint is $\gamma(\phi \lambda-k)-\lambda<0$. $2 /$ This is equivalent to the condition that, at a given real exchange rate, an exogenous increase in aggregate demand shifts the IS curve to the right in $r-y$ space.

Assuming that the conditions for the existence of a saddlepoint equilibrium are satisfied,

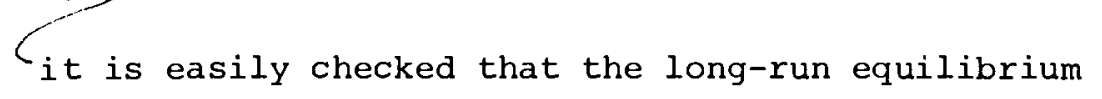
has the following properties. Output is equal to its full employment value, o. The steady-state real interest rate, $r-D p$ equals $r^{*}-D p^{*}+\tau=r^{*}+\tau$ since we assume that the foreign rate of inflation to be zero. The nominal interest rate $r$ equals $r^{*}+\tau+D e=r^{*}+\tau+D p-D p^{*}=r^{*}+\tau+D m-D p^{*}$. Long-run competitiveness is independent of $\mathrm{Dm}, \theta$ and $r_{\mathrm{d}}$ but improves when $r^{*}+\tau$ increases. The steady state stock of real money balances $\ell$ decreases 
when Dm or $r^{*}+\tau$ increase but increases when $\theta$ or $r_{d}$ increase.

We now briefly summarize the effects on competitiveness and output of a number of policy actions similar to the ones implemented by the Thatcher government. a) An unanticipated and immediately implemented reduction in the
rate of monetary growth.

There is no long-run effect on competitiveness associated with a reduction in the monetary growth rate. The steady-state stock of real money balances increases owing to the lower nominal interest rate associated with the lower steady-state rate of inflation. The dynamics are described in Figure 1. The reduction in $\mathrm{Dm}$ is implemented as soon as it is first anticipated. The initial long-run equilibrium is at $E_{1}$, the new one at $\mathrm{E}_{2}$ - For convenience we assume that the initial position is also at $\mathrm{E}_{1}$. To achieve convergence to the new equilibrium the nominal exchange rate jumps so as to put the system on the saddlepath SS' through $\mathrm{E}_{2}$. With $\mathrm{p}$ predetermined, a jump in $\mathrm{e}$ corresponds to a jump in $\mathrm{c}$. This

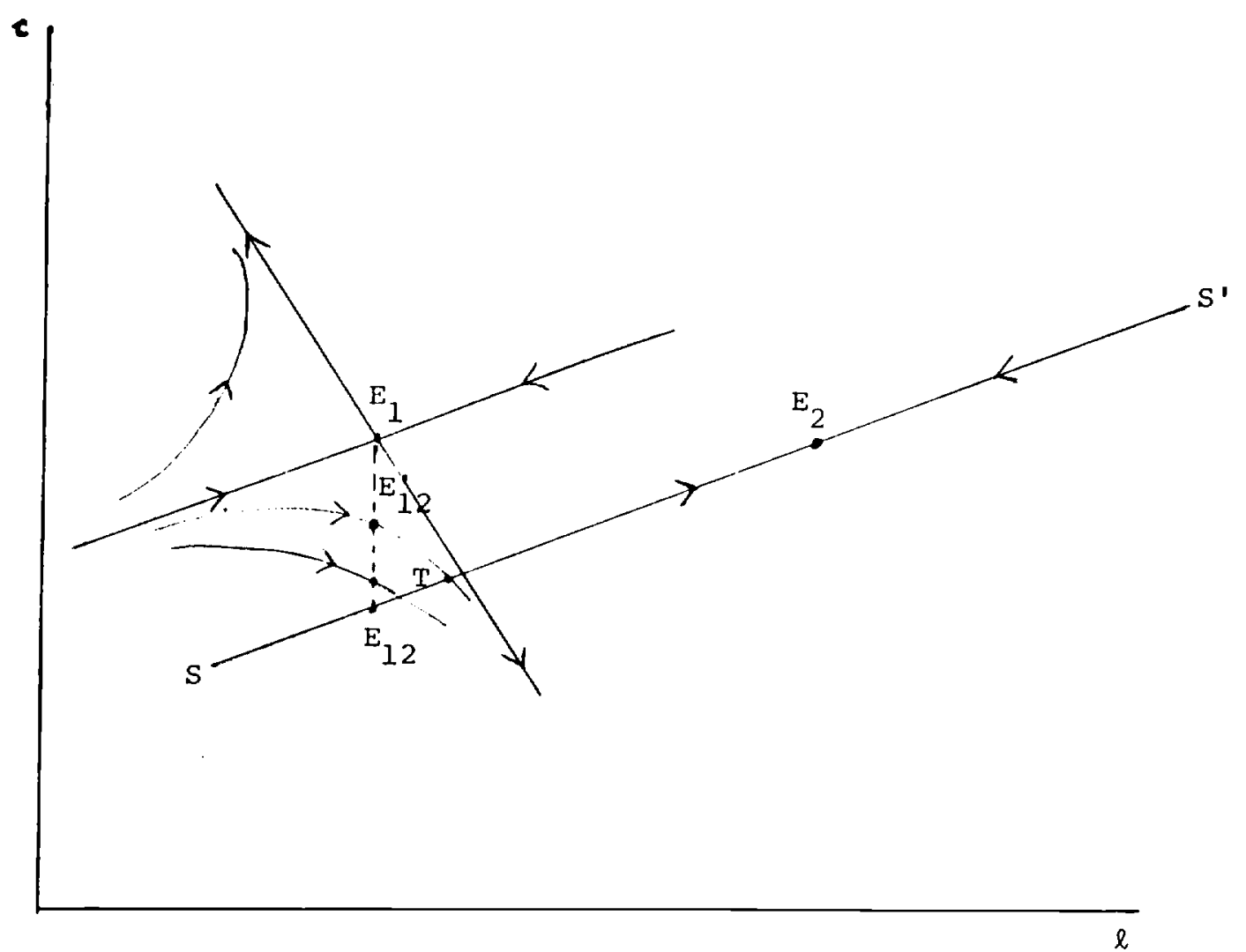


jump-appreciation of the real exchange rate to $E_{12}$ in response to an unanticipated reduction in the rate of monetary growth is associated with a decline in output and a fall in the nominal interest rate. Note from equations (3) and (4) that "on impact" the reduction in Dm lowers the rate of inflation by more than the change in the rate of growth of the money supply: cet. par. there is a one-for-one relationship between Dp and $\mathrm{Dm}^{+}$. The induced decline in output further lowers the rate of inflation. This somewhat implausible feature of the model will be removed below in Section 4 .

From the LM equation (1) it can be seen that with $r_{\mathrm{d}}$ and $\theta$ exogenous and $\ell$ predetermined, $r$ and $y$ have to move in the same direction in response to any exogenous shock. The nominal interest falls in response to the monetary growth deceleration, reflecting the current and anticipated future success of the anti-inflationary strategy. To equate the demand for money to its predetermined real supply, output falls. The reduction in output is achieved both through appreciation of the real exchange rate and through the increase in the real interest rate. $3 /$ To avoid the conclusion of our model that a reduction in the rate of growth of the money stock lowers the nominal interest rate, the money demand function would have to be modified. Possible modifications are the following. The inclusion of a long rate of interest in the money demand function. Even if the nominal interest rate on long term debt declines in response to the antiinflationary strategy, the short rate may rise in the short run. Similar conclusions for the behaviour of the short rate would follow if the (cxpected) rate of inflation were to have a negative effect on the demand for money. Finally, wealth effects on the demand for money could be included. A fall in the long term nominal interest rate means an upward 
revaluation of private sector holdings of long-dated public debt. This would raise the demand for money, thus rendering a decline in output consistent with an increase in the short nominal interest rate.

b) A previously unanticipated future reduction in the rate of monetary growth.

If the unanticipated reduction in monetary growth does not occur until an interval of length $T$ has lapsed after the announcement, the behaviour of $c$ and $l$ in Figure 1 follows the path $E_{1}-E_{12}^{\prime}-T-E_{2}$. When the "news" breaks there is a jump appreciation of the real exchange rate to $\mathrm{E}_{12}$. This places the system on that unique unstable trajectory, drawn with reference to the initial equilibrium, which will cause it to arrive on the unique convergent path SS' through $E_{2}$ after an interval of duration $T$. In the absence of further "news" no other discrete jumps in $e$ and $c$ occur, reflecting the assumption that the behaviour of risk-neutral speculators will eliminate anticipated future jumps in e , as these would be associated with infinite anticipated rates of capital gain or loss.

c) The medium term financial strategy

The medium term financial strategy (MTFS) of the Thatcher government had as its centrepiece an announced sequence of 4 annual one point reductions in the target range of monetary growth. Approximating the range by its central value, the response of the system to the unanticipated and immediate introduction of the MTFS can be depicted as in Figure 2. 4 If there were only a single unanticipated one point reduction in the rate of monetary growth, $c$ would jump immediately to $E_{12}$ on $S_{1} S_{1}$. If the entire 4 point reduction in Dm were to be implemented immediately, the system would jump to $E_{12}^{\prime}$ on $S_{4} S_{4}$. 


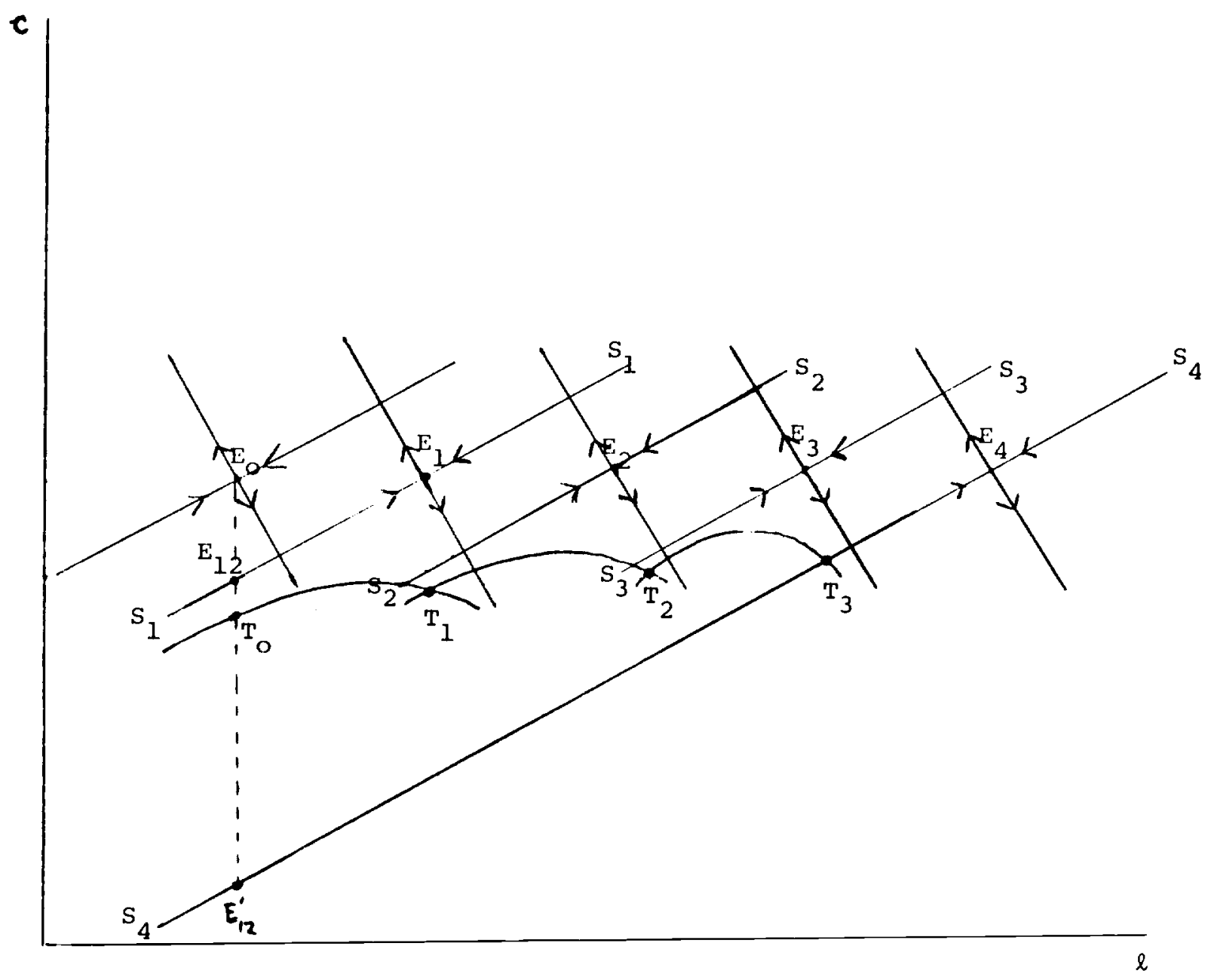

Figure 2 
The actual effect is intermediate between these two extremes. The initial jump in $c$ takes it beyond $E_{12}$ to a point such as $T_{0}$ because the magnitude of the initial jump in $c$ is a function of the announced future reductions in monetary growth. Under rational expectations the system must follow a path which will, without future jumps in competitiveness, put it on $\mathrm{S}_{4} \mathrm{~S}_{4}$ when the fourth and final year of the MTFS dawns. We assume that no further reductions in monetary growth are planned after the fourth year. If a non-inflationary rate of monetary growth is the long-term target and if the MTFS is likely to be extended to achieve this purpose, a further 5 or 6 years of successive one percentage point reductions in $\mathrm{Dm}$ should be added to the picture of Figure 2. The initial jump in $\mathrm{c}$ would be correspondingly greater. All this assumes of course that the inflationary mechanism, and more specifically the degree of nominal inertia in the level of $p$, remains unchanged, regardless of how far in advance monetary growth reductions are announced and irrespective of the degree of belief attached to these announcements. The four year MTFS leads in Figure 2 to immediate loss of competitiveness, which places the system at $T_{0}$ below $E_{12}$. After this there is a sequence of connected one-year-long paths $\left(T_{0}-T_{1}, T_{1}-T_{2}, T_{2}-T_{3}\right.$ ) which will place the system on the convergent path $\mathrm{S}_{4} \mathrm{~S}_{4}$ through $\mathrm{E}_{4}$ at the beginning of the fourth and final year of the MTFS. Each one-year-long path $T_{i}-T_{i+1}, i=0,1,2$, follows a divergent trajectory, drawn with reference to the long-run equilibrium $E_{i}$ because during the $i^{\text {th }}$ year the system is "driven" by the values of the forcing variables for that year. 
d) An unanticipated increase in indirect taxes

To model the important monetary aspects of the conservative government's fiscal policy, we consider a fiscally-neutral increase in the rate of indirect taxation, $\theta$. There is assumed to be no direct effect on aggregate demand because the increase in indirect taxes is matched by a reduction in direct taxes. The price equation "at factor cost" is assumed unaffected by the reduction in direct taxes. To justify this assumption for the wage component of factor costs, one could plausibly postulate a labour supply schedule that is perfectly inelastic with respect to the after-tax real wage. The long-run effect of an increase in $\theta$ is an increase in $\ell=m-p$ by the same amount as the increase in $\theta .5 /$ with the path of $m$ exogenous, prices net of indirect tax decline so that market prices follow their previous path and $\mathrm{m}-\mathrm{p}-\theta$ is unchanged in the steady state. The dynamic behaviour of the economy is described in Figure 3 . It is qualitatively the same as that following a reduction in Dm. The exchange rate jump-appreciates and output declines. Figure 3 also describes the

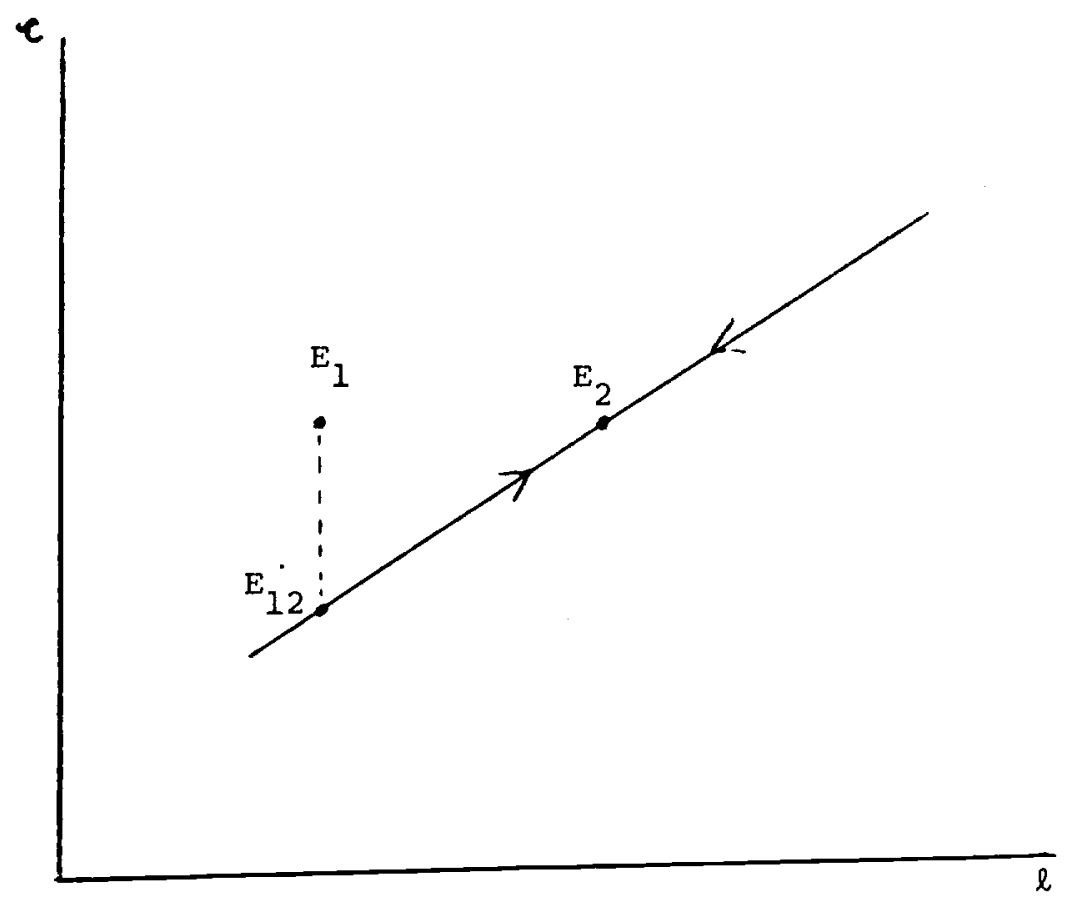


consequences of an unanticipated immediate increase in $r_{d}$. The abolition of the corset, which we model (crudely) as an increase in $r_{d}$, is estimated to have increased money demand by about $4 \%$.

e) An unanticipated increase in the level of the money stock

An unanticipated and immediately implemented once-and-for-all increase in $m$ does not alter the long-run equilibrium real money stock or level of competitiveness. With $p$ predetermined, an increase in $m$ is an increase in $\ell$. The behaviour of the economy when subjected to such a shock is described in Figure 4. The initial and final equilibrium are both at $E_{1}$. The initial real money stock is $\ell_{1}=m_{1}-p_{1}$. The unanticipated increase in $m$ raises the real money stock to $\ell_{2}=m_{2}-p_{1}$, $m_{2}>m_{1}$. The real exchange rate jump-depreciates to $E_{12}$ to place the system on the convergent saddlepath SS' through $E_{1}$ - Output expands and the nominal interest rate falls on impact. Note the difference between an increase in $m$ and an increase in Dm. Both are expansionary in the

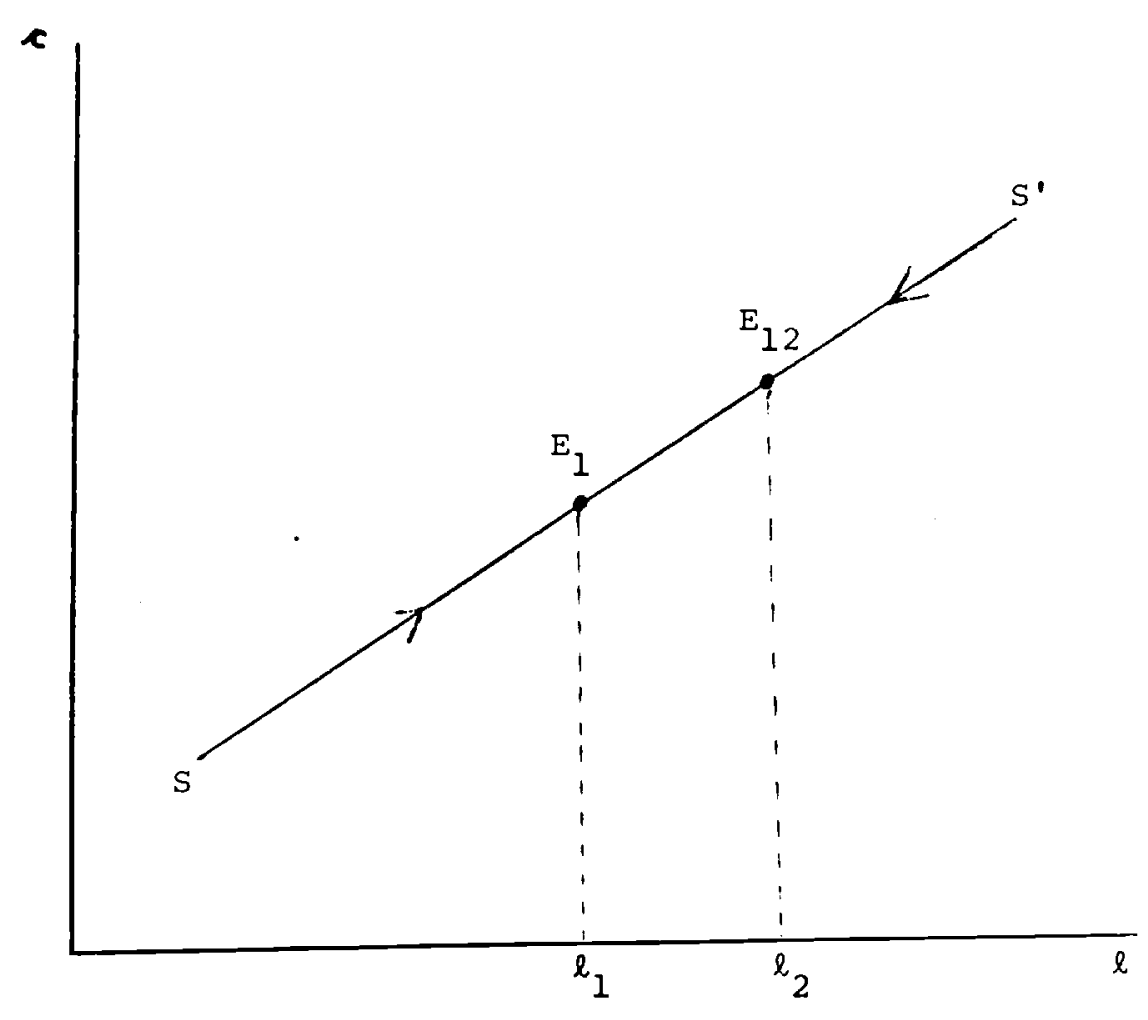


short-run, but while an increase in Dm raises the nominal interest rate, an increase in $\mathrm{m}$ lowers it. Neither policy action affects long-run competitiveness, but while a once-and-for-all increase in the level of the nominal money stock leaves long-run real balances unchanged, an increase in the rate of growth of the nominal money stock will, by raising inflation and the nominal interest rate, reduce the long-run stock of real money balances.

Comparing Figure 4 with Figures 1 and 3 suggests a way of avoiding the excess capacity and the loss of competitiveness associated with policies to reduce the rate of inflation by reducing the rate of monetary growth and with switches from direct to indirect taxation. Consider an initial equilibrium at $E_{1}$ in Figure 5. An unanticipated immediate reduction in Dm (or increase in $\theta$ or $r_{d}$ ) would, by itself, move the economy to $E_{12}$, with real exchange rate appreciation and excess capacity resulting during the transition to the new long-run equilibrium $E_{2}$. The reason for this costly disequilibrium adjustment is stickiness of the real money supply. This is the result of the combination of price level stickiness,

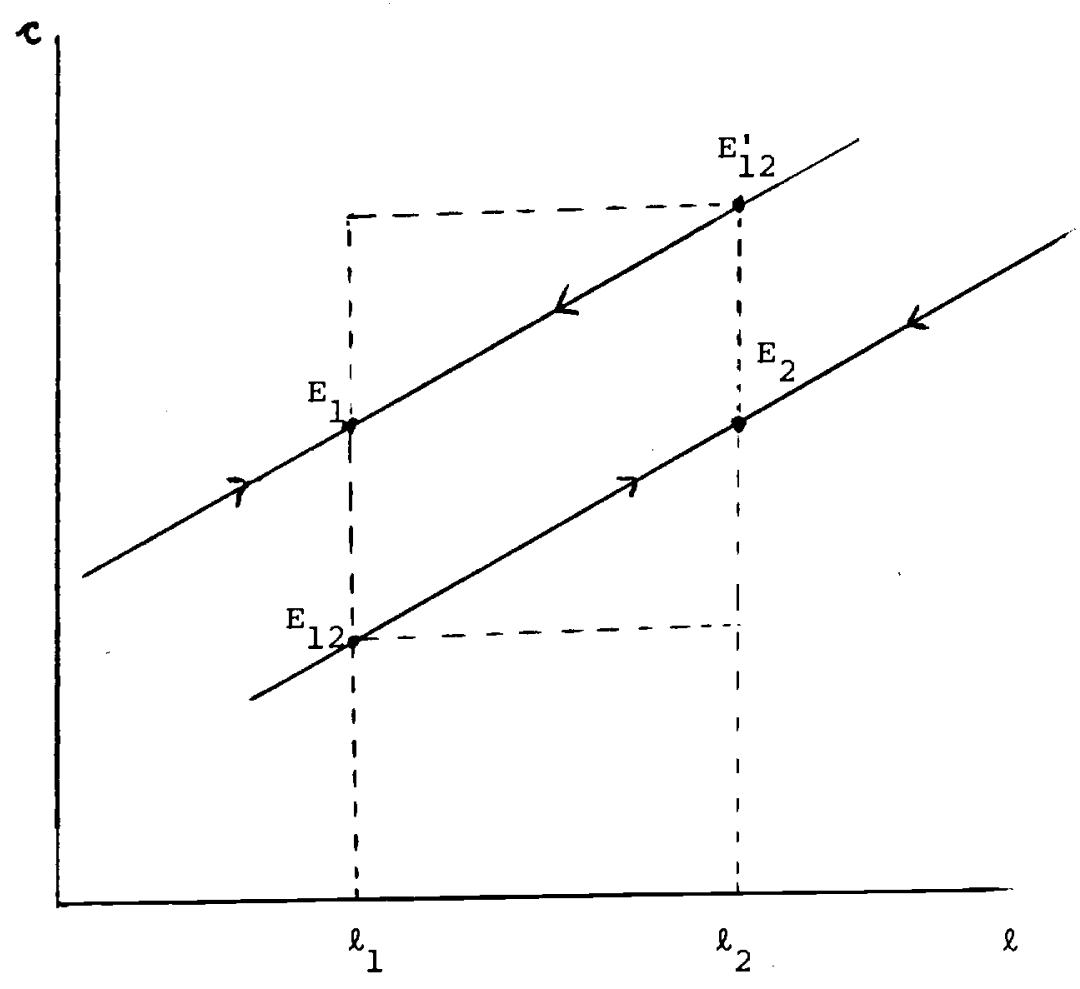

Figure 5 
an assumed feature of the private economy, and stickiness in the level of the nominal money stock, the result of a deliberate policy choice. It is easy in the present model to calculate the increase in the level of the nominal money stock that would immediately achieve the required long-run increase in real balances without any need for the price level path to be adjusted downward. Without a "jump" in the level of the nominal money stock the price equation $D p=\phi y+D^{+} m$ tells us that the only way of lowering $p$ relative to $\mathrm{m}$ is through excess capacity. The required nominal money stock jump is simply $\ell_{2}-\ell_{1}$. By itself, an increase in $m$ by that amount would move the system to $E_{12}^{\prime}$. A combindation of a reduction in Dm (or an increase in $\theta$ or in $r_{d}$ ) and an increase in $m$ of the right magnitude will immediately and without transitional loss of competitiveness and output, place the economy at $E_{2}$. The jump appreciation associated with the reduction in the rate of monetary growth, the increase in indirect taxation or the increased competitiveness of the ba rking system, and the jump depreciation associated with the increase in the level of the money stock cancel each other out exactly. It can be argued that the government's decision not to try to recoup the large overshoot during the second half of 1980 of the $\{M 3$ target amounts to an (involuntary) m-jump of the kind advocated here. Whatever the motivation, it has prevented a further massive deflationary jolt to an economy already going through the worst recession since the 1930 's.

3. Real Exchange Rate Overshooting and the Wage-price Process

A crucial component of all models exhibiting disequilibrium overshooting of the real exchange rate is the wage-price process. The price equation used in the paper so far, as in many others (e.g. Buiter and Miller [1981], Dornbusch [1976]) has a number of weaknesses. It is important to perform 
a "sensitivity analysis" of the specification of this equation in order to establish the robustness of the overshooting proposition.

a) A direct effect of the exchange rate on the domestic price level Even if domestic wage costs are sticky in nominal terms, so that the money wage rate, $w$, can be treated as predetermined, the domestic price level might in an open economy still be capable of making discrete jumps at a point in time. This will be the case if the domestic currency price of internationally traded goods is a function of the exchange rate.

A convenient way of representing this notion is to express the domestic price level, $p$, as a weighted average of the sticky domestic money wage and the domestic currency value of an appropriate (trade-weighted) index of world prices, $\mathrm{p}^{*}$. Making the small country assumption that $\mathrm{p}^{*}$ is given and choosing units such that $\mathrm{p}^{\star}=0$ we have:

$$
p=\alpha w+(1-\alpha) e \quad 0 \leqslant \alpha \leqslant 1 .
$$

Equation (3) is then replaced by:

$$
D w=\phi y+\pi
$$

For the time being we still assume that

$$
\text { (4) } \pi=D^{+} \mathrm{m} \text {. }
$$

With $\alpha<1$, the domestic price level is no longer predetermined. The jump appreciation of the nominal (and real) exchange rate in response to e.g. an unanticipated reduction in the rate of monetary growth will have the immediate effect of lowering the price level. However, as long as $\alpha>0$, the earlier analysis is not affected qualitatively. We redefine our state variables as follows: 
(10a) $\quad \ell=m-w$

(10b) $\quad c=e-w$

As before, $\ell$ is predetermined (except when $m$ jumps) and $c$ is a jump variable. The state space representation of the model given in equations (1), (2), (8), (9), (4) and (5) is:

$$
\left[\begin{array}{c}
\mathrm{D} \ell \\
\mathrm{DC}
\end{array}\right]=\frac{1}{\alpha \gamma(\lambda \phi-\mathrm{k})-\lambda}\left[\begin{array}{cc}
\phi \alpha \gamma & \phi \alpha(\lambda \delta-\gamma(1-\alpha)) \\
1 & \alpha \delta(\phi \lambda-\mathrm{k})+\alpha-\underline{1}
\end{array}\right]\left[\begin{array}{l}
\ell \\
\mathrm{C}
\end{array}\right]
$$

$$
+\frac{1}{\alpha \gamma(\lambda \phi-\mathrm{k})-\lambda}\left[\begin{array}{cccc}
\alpha \gamma(\lambda \phi-\mathrm{k})-\lambda & -\phi \lambda \gamma(1-\alpha) & -\phi \alpha \gamma & -\phi \alpha \gamma \lambda \\
0 & \lambda+\gamma(k-\phi \lambda) & -1 & -\lambda
\end{array}\right]\left[\begin{array}{c}
D \mathrm{~m} \\
r^{*}+\tau \\
\theta \\
r_{d}
\end{array}\right]
$$

It is easily seen that (7) is the special case of (11) with $\alpha=1$.

A necessary and sufficient condition for the existence of a unique saddle-point equilibrium is $\alpha \gamma(\lambda \phi-k)-\lambda<0$, which again has the interpretation that, at a given level of competitiveness, an increase in aggregate demand shifts the IS curve to the right. The single convergent path is again upwardsloping and the real exchange rate overshooting results of section 2 carry over to the more plausible model under consideration here. The main change from the previous analysis with $\alpha=1$, is that the exchange rate appreciation consequent upon restrictive monetary policy actions (or increases in $\theta$ or $r_{d}$ ) now has an immediate beneficial effect on the price level although as long as $\alpha>0$, a given percentage appreciation of e will be associated with a smaller percentage reduction in $p$. 
The special case $\alpha=0$ represents the "law of one price" for all goods or instantaneous purchasing power parity (P.P.P.). Although few propositions in economics have been rejected more convincingly by the data than P.P.P. (Kravis and Lipsey [1978], Frenkel [1981], Isard [1977]) it is mentioned briefly for completeness. With the domestic price level moving perfectly in line with the exchange rate, the wage equation (9) which still incorporates stickiness in the level of the money wage, ceases to be relevant to the rest of the model. The relative price of domestic and foreign goods is constant. Real output is a function of the exogenous real interest rate. Unless we impose the requirement that steady-state real wages are constant, output need not be at its full employment level. Alternatively we could add an equation making output a (decreasing) function of the real wage. As this model has little to recommend it, we shall not pursue it any further here.

\section{b) Money wage flexibility and real wage flexibility}

We now consider the case where both the money wage and the real wage are perfectly flexible, and output is always at its equilibrium or capacity value, 0 . We can view this as the case where the core rate of wage inflation, $\pi$, equals the expected (and actual) rate of wage inflation, i.e. (4') $\quad \pi=\mathrm{DW}$.

The model of equations (1), (2), (8), (9), (4') and (5) has the following very simple state-space representation: 


$$
\left[\begin{array}{l}
\mathrm{D} \ell \\
\mathrm{DC}
\end{array}\right]=\left[\begin{array}{ll}
\lambda^{-1} & \gamma^{-1} \delta-(1-\alpha) \lambda^{-1} \\
0 & \gamma^{-1} \delta
\end{array}\right]\left[\begin{array}{l}
\ell \\
c
\end{array}\right]
$$

$$
+\left[\begin{array}{cccc}
1 & -\alpha^{-1}(1-\alpha) & -\lambda^{-1} & -1 \\
0 & -\alpha^{-1} & 0 & 0
\end{array}\right]\left[\begin{array}{c}
D m \\
r^{*}+\tau \\
\theta \\
r_{d}
\end{array}\right]
$$

With both $e$ and $w$ freely flexible, neither of the two state variables $\ell$ and $C$ is predetermined. A unique convergent solution trajectory exists because there are now two unstable characteristic roots $\left(\lambda^{-1}\right.$ and $\left.\gamma^{-1} \delta\right)$. The system is also recursive, with $D C$ independent of $\ell$ and also of the policy instruments $\mathrm{Dm}, \mathrm{r}_{\mathrm{f}}$ and $\theta$. Only a real shock (such as a change in the foreign real interest rate $r^{*}+\tau$ ) will affect the dynamics and steady state behaviour of $c$.

The diagrammatic representation of the system is given in Figure 6 . Without loss of generality we assume that the $D l=0$ locus is downwardsloping. Consider an unexpected, immediately-implemented reduction in Dm. The initial equilibrium is at $E_{1}$, the new equilibrium at $E_{2}$. Note that these equilibria are completely unstable. Since the cut in the monetary growth rate is immediately implemented, $\&$ jumps immediately from $E_{1}$ to $\mathrm{E}_{2}$ with no change in $\mathrm{c}$. Monetary disinflation is costless. If we consider a previously unanticipated future reduction in Dm, $\ell$ will jump to an intermediate position like $E_{12}$ between $E_{1}$ and $E_{2}$ at the moment the future policy change is announced. After that it moves gradually in a straight line from $E_{12}$ to $E_{2}$ where the system arrives at the moment that $\mathrm{Dm}$ is actually reduced. Again there is no effect on competitiveness in the short run or in the long run. 


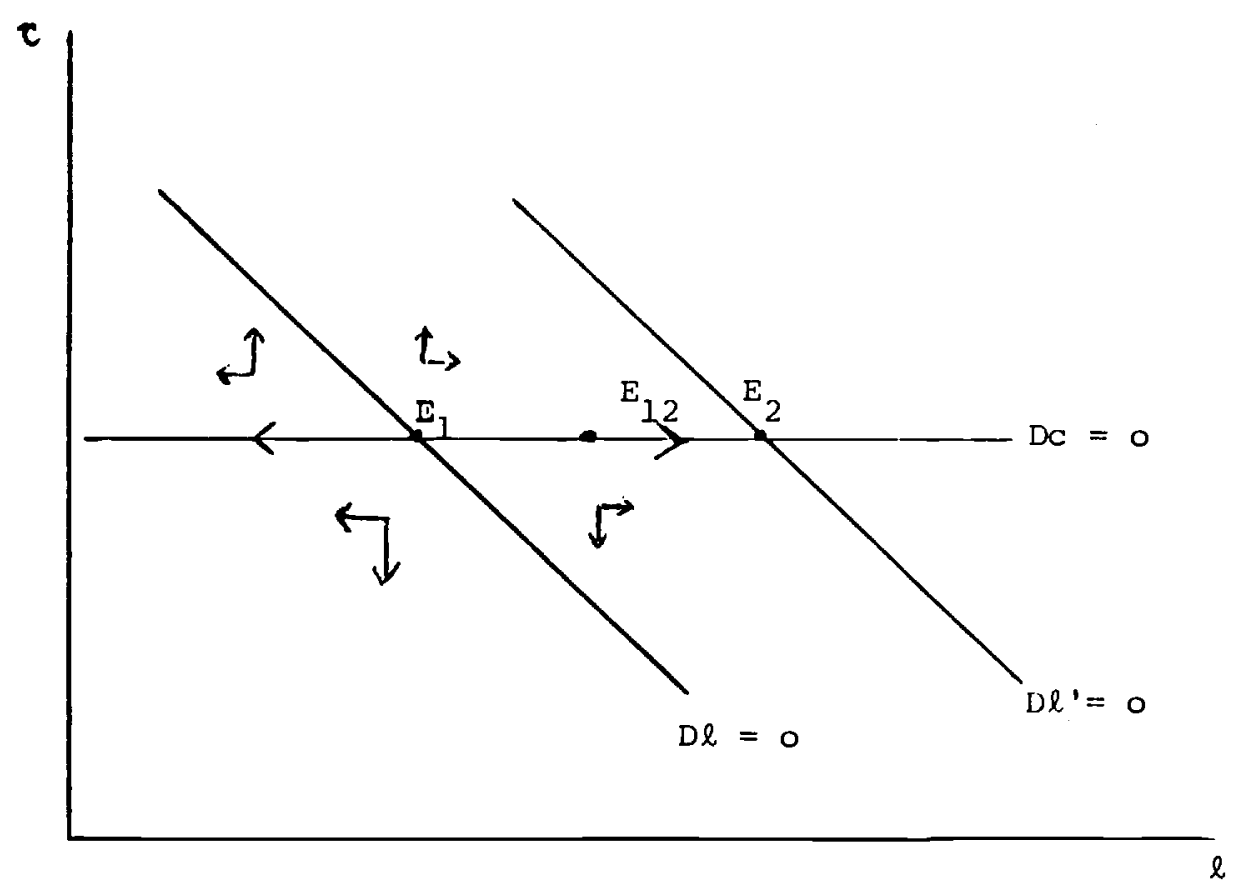

Figure 6

It is instructive to contrast monetary disturbances with a real shock such as an increase in $r^{*}+\tau$, analysed in Figure 7 . The steadystate effect is to alter the long-run equilibrium from $E_{1}$ to $E_{2}$, lowering $\ell$ and raising $c$. If the increase in $r^{*}+\tau$ occurs immediately both $\mathrm{c}$ and $\ell$ jump to $E_{2}$ without delay. If we have a future increase in $r^{*}+\tau$, the system jumps to an intermediate position such as $E_{12}$ after which it proceeds gradually to $E_{2}$ where it arrives when $r^{*}+\tau$ is actually raised. Note that this adjustment of the real exchange rate is an equilibrium phenomenon, taking place at a constant level of output. There is never any effect on competitiveness of monetary shocks. 


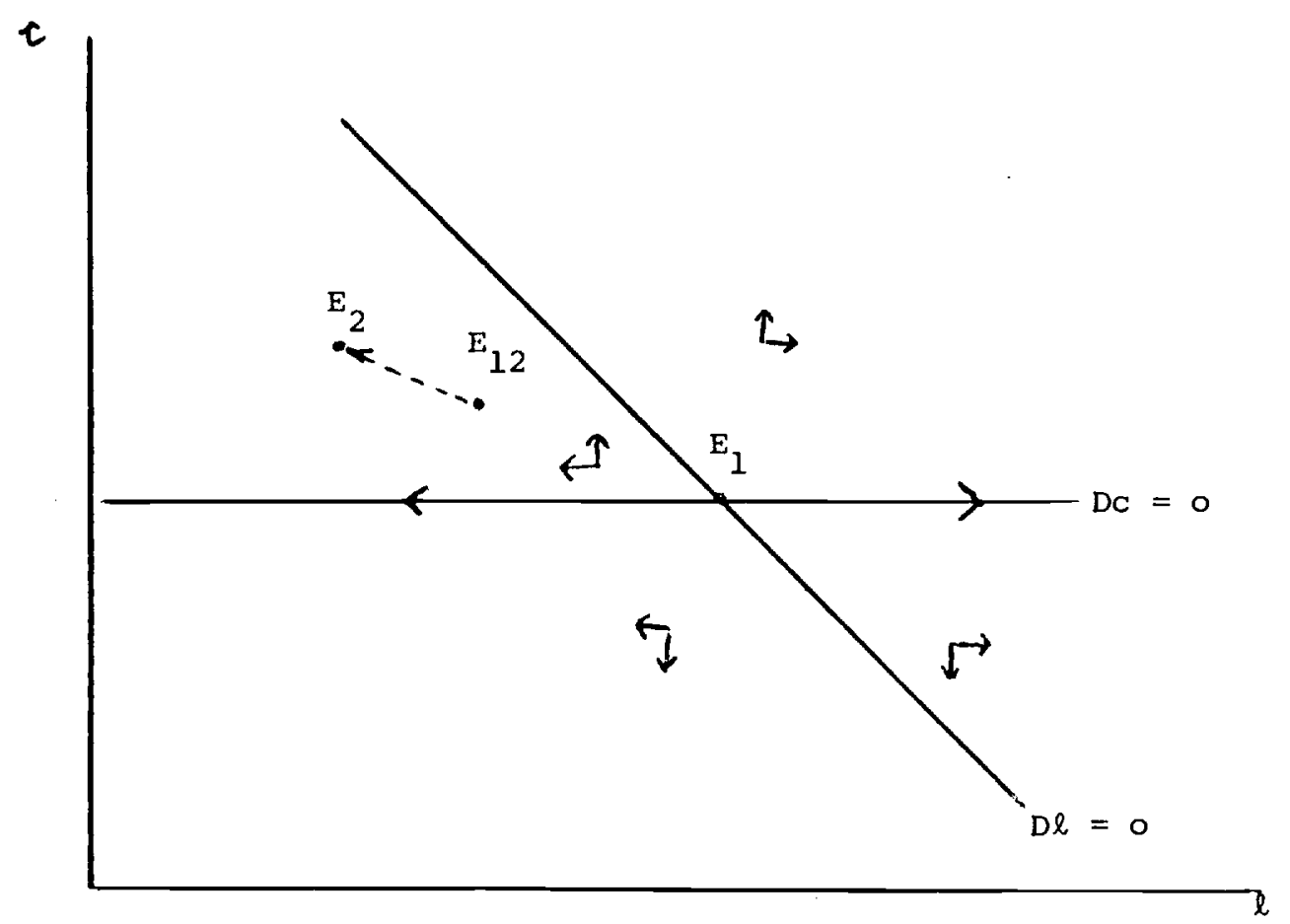

Figure 7

c) Money wage flexibility and real wage rigidity

Some recent work on wage and price behaviour can be interpreted as combining the assumption of perfectly flexible money wages with the assumption of sluggish adjustment in the real wage. The latter is treated as predetermined because of (generally unspecified) transactions and adjustment costs.

Consider e.g. the following specification for $\pi$

(4') $\pi=D p-\eta(w-p) \quad \eta \geqslant 0$

Equation (4'), in combination with (9) yields

(14) $\quad D w=\phi y+D p-n(w-p)$

or

(14') $D(w-p)=\phi y-n(w-p)$ 
Equation (14) can be viewed as a rational expectations version of the kind of equation proposed by Sargan [1980]. It is also very close to an equation found in Minford [1980] although his equation incorporates nominal stickiness. The state-space representation of the model with nominal flexibility and real stickiness is given in equation (15) below:

(15) $\left[\begin{array}{c}D \ell \\ D c\end{array}\right]=\left[\begin{array}{cc}\lambda^{-1} & -\frac{(1-\alpha)[\eta \lambda+k \alpha \gamma \eta+1-\alpha(1+\gamma \phi)+\alpha \delta k]+\alpha \delta \phi \lambda}{\lambda(1-\alpha(1+\gamma \phi))} \\ 0 & -\frac{[\eta(1-\alpha)+\phi \alpha \delta]}{1-\alpha} \frac{(1+\gamma \phi)}{l}\end{array}\right]\left[\begin{array}{l}\ell \\ c]\end{array}\right]$ $\left[\begin{array}{cccc}1 & \frac{\lambda[1-\alpha(1+\gamma \phi)]+\lambda \phi \gamma+k \gamma(1-\alpha)}{\lambda[1-\alpha(1+\gamma \phi)]}-\lambda^{-1} & -1 \\ 0 & \frac{\phi \gamma}{1-\alpha(1+\gamma \phi)} & 0 & 0\end{array}\right]\left[\begin{array}{c}\mathrm{Dm} \\ r^{*}+\tau \\ \theta \\ r_{d}\end{array}\right]$

Note that real wage rigidity implies real exchange rate rigidity, as $w-p=(\alpha-1) c$. With a flexible money wage, $\ell$ now is a jump variable. The roles of $l$ and $c$ as predetermined and jump variables is the exact reverse of what it is in the model with sticky money wages (and flexible real wages) of Section 2. The two characteristic roots of equation (15) are $\lambda^{-1}$ and $-\frac{[\eta(1-\alpha)+\phi \alpha \delta]}{1-\alpha(1+\gamma \phi)}$. The sign of the second root -- the one governing the behaviour of $c--$ depends on the sign of $1-\alpha(1+\gamma \phi)$. This has the following interpretation. Add an exogenous demand shock $f$ to the Is equation (2). This yields $y=-\gamma(r-D p)+\delta(e-p)+f$. It is readily checked that 
(16a) $e-p=\alpha_{c}$

(16b) $\quad r-D p=r^{*}+\tau+\alpha D C$

and

(16c) $\quad D C=\frac{\phi}{\alpha-1} y-n c$.

The IS curve can therefore be written as

$$
y=-\frac{\gamma(1-\alpha)}{1-\alpha(1+\gamma \phi)}\left(x^{*}+\tau\right)+\frac{\alpha(1-\alpha)(\gamma \eta+\delta)}{1-\alpha(1+\gamma \phi)} c+\frac{(1-\alpha)}{1-\alpha(1+\gamma \phi)} f
$$

For $0 \leqslant \alpha<1,1-\alpha(1+\gamma \phi)$ must be positive if an exogenous increase in demand is to raise output at a given level of competitiveness. We shall make this assumption. It implies that the root governing $c$ is negative. Note that with equation (14') governing the behaviour of the real wage, there is no automatic tendency for the level of output to converge to its capacity level 0 . In long-run equilibrium we have (setting $D(w-p)=0$ ), (17) $\quad y=\frac{\eta}{\phi}(w-p)=(\alpha-1) \frac{\eta}{\phi} \mathrm{c}$ The system is still dichotomized, and the behaviour of c, w-p, $y$ and $r-D p$ is independent of monetary shocks, but even if we start at full employment, real shocks will not necessarily be followed by a return to full employment. Only if $n$ (- the coefficient on the lagged real wage in the wage equation) is zero will the system tend to full employment. This can be shown as follows. In long-run equilibrium the Is equation is

$$
y=-\gamma\left(r^{*}+\tau\right)+\delta \alpha c+f
$$

Combining (17) and (18) gives 


$$
y=\frac{(\alpha-1) \eta \gamma}{\phi \delta \alpha-(1-\alpha) \eta}\left(r^{*}+\tau\right)-\frac{(\alpha-1) \eta \delta \alpha}{\phi \delta \alpha-(1-\alpha) \eta} \mathbf{f}
$$

Apart from the absence of an automatic return to full employment the behaviour of the flexible money wage-sticky real wage model is qualitatively the same when $\eta=0$ and when $n>0$. The response to an unanticipated reduction in $\mathrm{Dm}$ is shown in Figure 8.

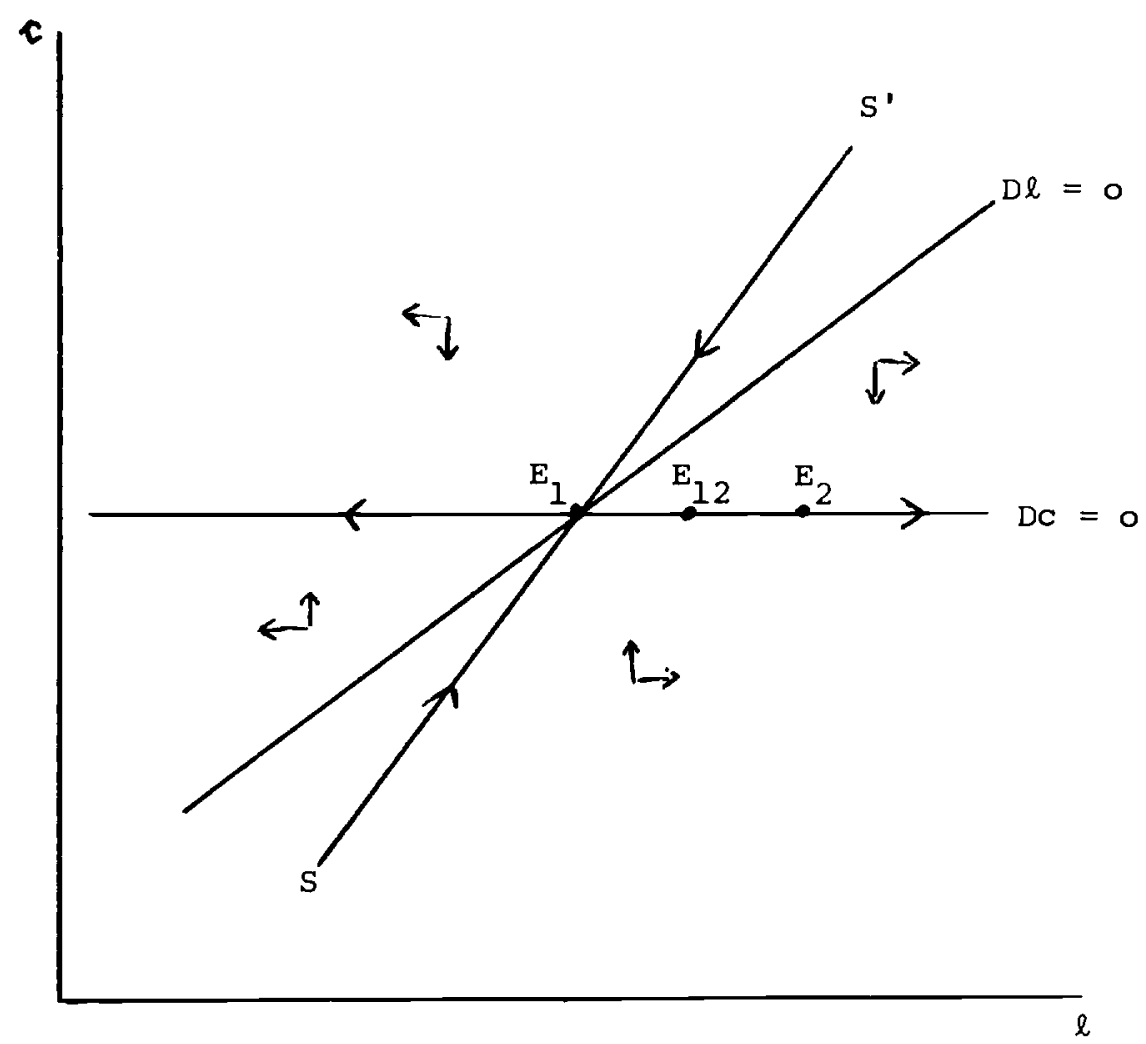

Figure 8

An unanticipated immediately-implemented reduction in $\mathrm{Dm}$ instantaneously moves the system to the new stationary equilibrium $E_{2}$ without any change in $c, y$ or $\mathbf{r}-\mathrm{Dp}$. An announced future reduction in Dm instantaneously moves the system to an intermediate position such as $E_{12}$, between $E_{1}$ and $E_{2}$ from where it moves gradually to $E_{2}$ where it arrives at the moment that the reduction in Dm actually occurs. This whole process again takes place without any changes in $\mathrm{c}, \mathrm{y}$ or $r-D p$. 
Now consider the effect of an increase in $r^{*}+\tau$ in this model, which changes the long-run equilibrium in Figure 9 from $E_{1}$ to a point such as $\mathrm{E}_{2}$

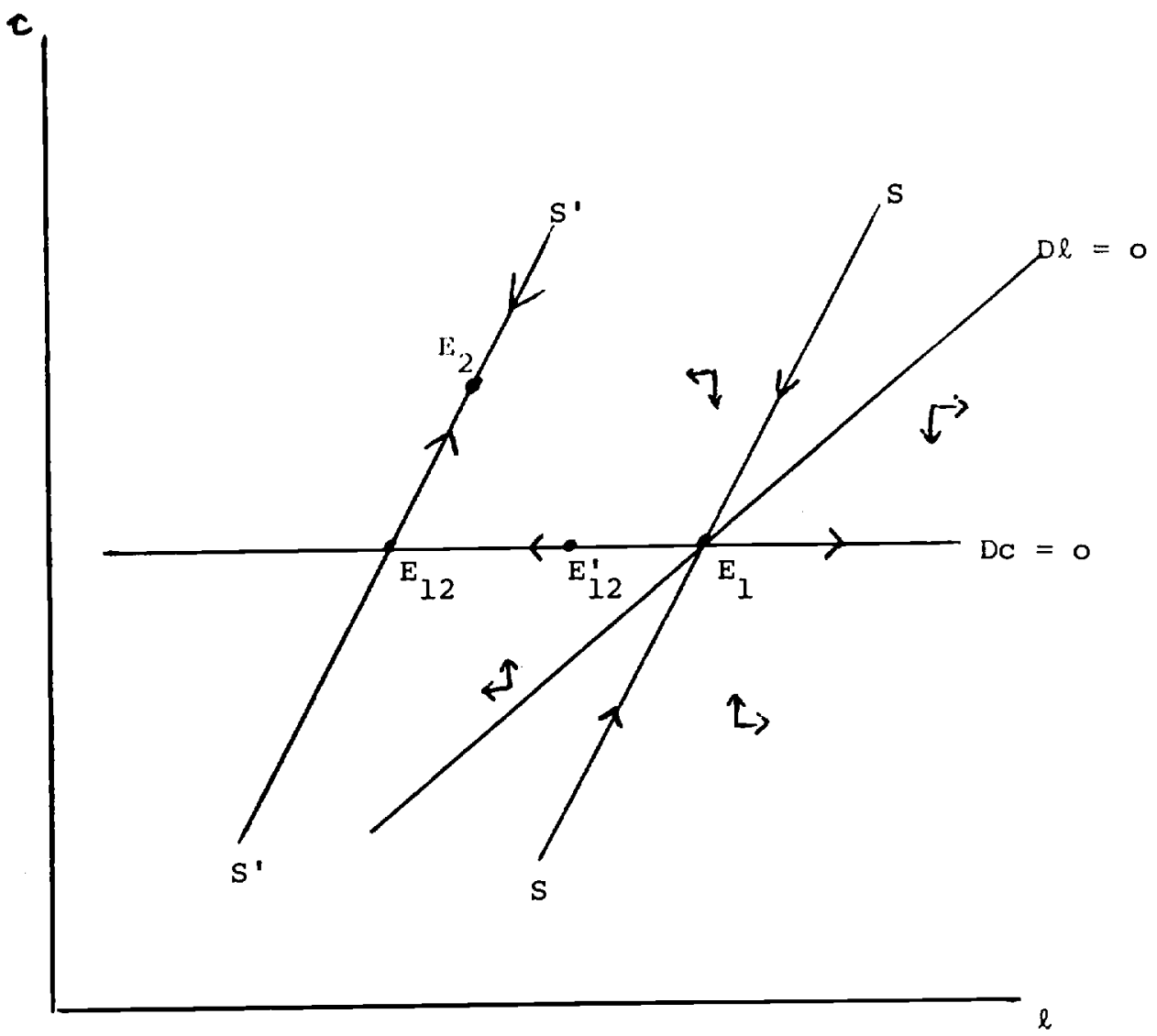

Figure 9

With $\mathrm{c}$ predetermined, an immediate unanticipated increase in $r^{*}+\tau$ causes an equal jump increase in $e$ and $w$, lowering $\ell$ to $\mathrm{E}_{12}$. From there $c$ and $\ell$ converge gradually to the new long-run equilibrium. $\mathrm{E}_{2}$ along the unique convergent trajectory S'S'. A 
previously unanticipated future increase in $r^{\star}+\tau$ leads to an immediate jump in $\ell$ down to an point intermediate between $E_{1}$ and $E_{12}$, such as $E_{12}^{\prime}$. From there $\ell$ declines gradually to $E_{12}$ where it arrives when $r^{*}+\tau$ is actually raised. $c$ and $\ell$ then increase gradually along SS' towards $\mathrm{E}_{2}$.

It is interesting to see that happens to the wage equation (14') when the exchange rate has no effect on the price level, i.e. when $\alpha=1$. In that case the price equation (8) becomes

(20a) $p=w$

while the wage equation reduces to

(20b) $\phi y=n(w-p)$

Equations $(20 a, b)$ imply that $y=0$ at each instant. The model now is in many ways the same as the model with money wage and real wage flexibility discussed in section $3 b$ and summarized in equation (13). The link between the real wage and the real exchange rate, given by $w-p=(\alpha-1) c$ in the general model, disappears. Even though the real wage is still predetermined (and indeed remains constant throughout at 0 ), the real exchange rate again becomes a jump variable. Because $w$ still is a jump variable, $\ell$ also stays that way. The state-space representation of this version of the model is given in (21)

$$
\left[\begin{array}{c}
D \ell \\
D c
\end{array}\right]=\left[\begin{array}{ll}
\lambda^{-1} & \gamma^{-1} \delta \\
0 & \gamma^{-1} \delta
\end{array}\right]\left[\begin{array}{l}
\ell \\
c
\end{array}\right]+\left[\begin{array}{llll}
1 & 0 & -\lambda^{-1} & -1 \\
0 & 0 & 0 & 0
\end{array}\right]\left[\begin{array}{c}
D m \\
r^{*}+\tau \\
\theta \\
r_{d}
\end{array}\right]
$$


The response of this system to nominal and real shocks is qualitative similar to that described in section $3 b$ and Figures 6 and 7 .

d) Rational expectations in the labour market with money wage stickiness Without changing the equation for the core rate of inflation (4'') and the associated wage equation (14) of the previous section, a single change of assumption concerning the behaviour of the money wage destroys the classical policy implications of that model. The crucial change in assumption is to rule out discrete jumps in $w$, that is to require $w$ to be a continuous function of time. The exchange rate, however, is still free to make discrete jumps at a point in time. This change in assumption does not rule out a rational expectations interpretation of (14). This is particularly obvious if we assume that $\eta=0$. The behaviour of this rational expectations model of the labour market is, however, very different from the classical behaviour of the models of sections $3 b$ and $3 c$. Instead it resembles the behaviour of the sticky money wage model of section 2 and $3 a$. Monetary shocks lead to real exchange rate overshooting and departures of actual from capacity output. Note that this kind of behaviour is ruled out when $\alpha=1$. This "closed economy" representation means that rational expectations automatically rule out departures of output from capacity output. 그 with the assumed asymmetry in the behaviour of $c$ and $w$, and with a direct effect of $e$ on $p$, monetary shocks will alter the real wage and the real exchange rate and cause departures from full employment.

With the sticky money wage interpretation of equation $(14), \quad \ell$ and $c$ again assume the roles of section $2 . \quad \ell$ is predetermined while $c$ (via e) can jump in response to "news".

The response of the system to an unanaticipated reduction in Dm is sketched in Figure 10. 


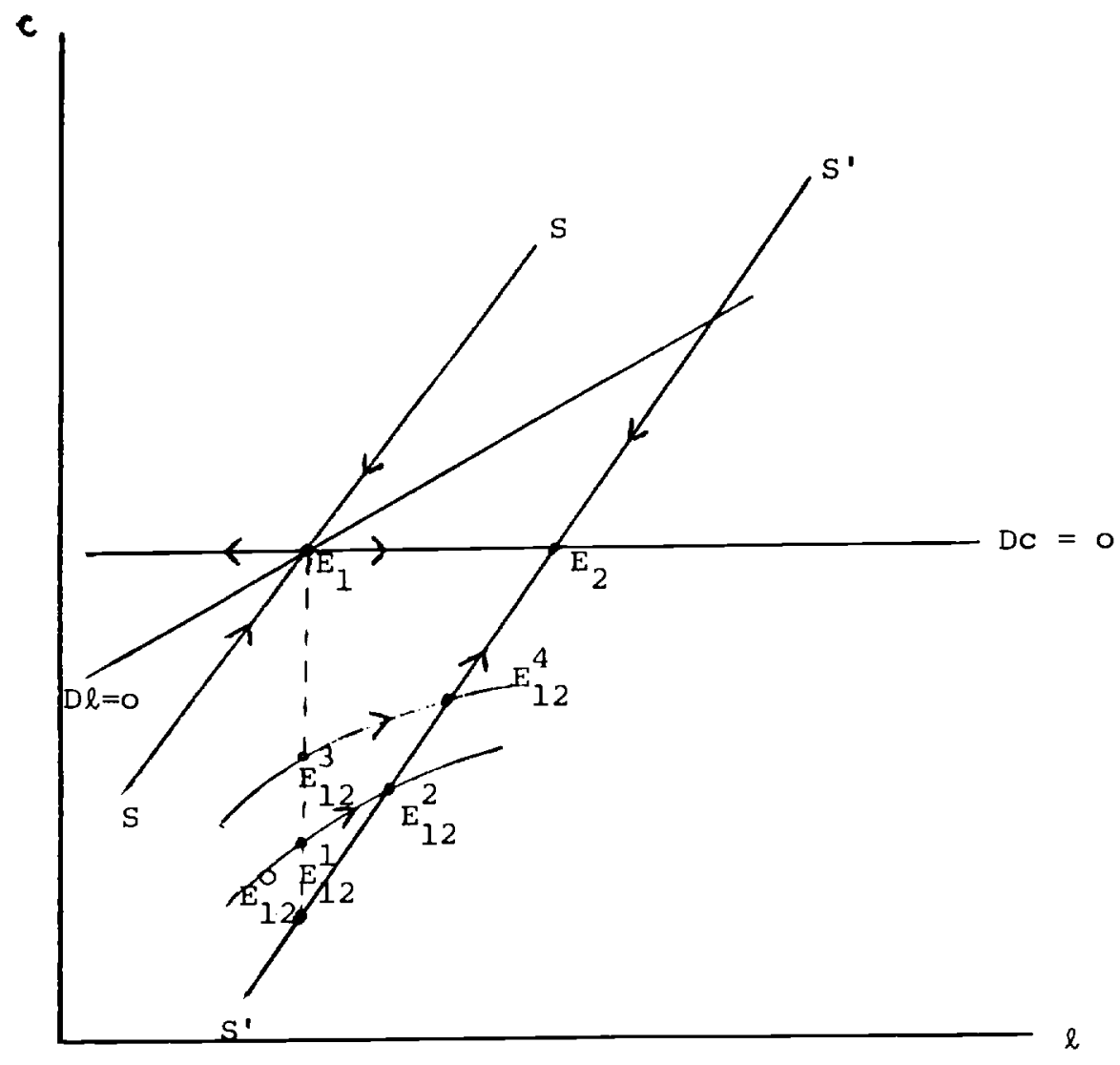

Figure 10

If the reduction in Dm takes place immediately c jump appreciates to $E_{12}^{\circ}$. After that it moves gradually to $E_{2}$ along S'S'. From equation (16d) we see that this jump-appreciation of $c$ will be associated with a fall in output. An anticipated future reduction in $\mathrm{Dm}$ will be associated with a smaller immediate jump-appreciation of $c$ when the news 
arrives, to $E_{12}^{\mathrm{l}}$ say. This jump places $\mathrm{c}$ and $\ell$ on the divergent path, driven by the values of the forcing variables determining $E_{1}$ that will put it on the convergent path through $E_{2}$ (S'S') when the cut in Dm is actually implemented. An equal reduction in $\mathrm{Dm}$ at a more distant future time will again be associated with a smaller initial jump-appreciation of $C$ (to $E_{12}{ }^{3}$ say) after which $C$ and $\ell$ follow the unstable trajectory (drawn with reference to $E_{1}$ ') that will put it on S'S' when $D m$ is actually cut. There always wll be a finite initial juml, in $c$ when the news of a future reduction in Dm arrives, except in the limiting case when the announced monetary growth reduction is infinitely far in the future. One implication is that if a monetary deceleration is planned, the loss of output and competitiveness is smaller the further in advance the proposed policy action is announced.

From equation (16c) with $n=0$ we obtain:

$$
y=\frac{\alpha-1}{\phi} D C
$$

. Assume the system starts in long-run equilibrium at $t=0$. The net cummulative loss of output $\frac{8}{}$ following a monetary deceleration is

$$
\int_{0}^{\infty} y(t) d t=\frac{\alpha-1}{\phi}[c(\infty)-c(0)] .
$$

$c(\infty)$ is the steady-state real exchange rate which is the same in the initial and the final long-run equilibrium. $c(\infty)-c(0)$ is therefore just the initial jump in the real exchange rate. The cummulative loss of output is minimized by minimizing the initial jump in c. This is achieved, for a given proposed reduction in $\mathrm{Dm}$ by announcing the reduction as early as possible. 
The assumption made so far, that $w(t)$ is a continuous function of time can be derived from two more basic assumptions. The first is that $w(t)$ cannot jump instantaneously in response to new information. In principle this would still permit discrete jumps in $w(t)$ at some $t>t_{0}$, where $t_{0}$ is the instant at which new information becomes available. The second assumption is an arbitrage condition for the labour market, which asserts that efficient speculative behaviour in the labour market climinates all profit opportunities associated with anticipated future jumps in $w$. This assumption is analogous to the arbitrage condition we have used to rule out anticipated future jumps in $e$, although its application to the labour market is rather less convincing than its use in tha foreign exchange market.

e) Gradual adjustment of core inflation with occasional jumps

The final specification of the equation for the core rate of inflation that we shall consider is given in equation (4'")

(4"') $\quad \mathrm{D} \pi=\xi(\mathrm{Dp}+\mathrm{D} \theta-\pi) \quad \xi>0$.

This adaptive process for $\pi$ does not rule out discrete jumps in $\pi$, although it is consistent with our assumption that the level of the money wage is predetermined. Equation (4"') defines $\pi$ as a backward-looking weighted average of past rates of inflation with exponentially declining weights 
$\pi(t)=\xi \int_{-\infty}^{t} e^{-\xi(t-s)}(D p(s)+D \theta(s)) d s$

Because $\pi(t)$ is backward-looking it will be associated with a stable eigenvalue. It is, however, not predetermined. $\pi(t)$ depends also on current $D p(t)$ and $D \theta(s)$. If $p+\theta$ makes a discontinuous jump at $t=\bar{t}, D p+D \theta$ becomes unbounded and so does $D \pi \cdot \pi$ therefore jumps. This characteristic of $\pi$ as a "dependent" jump variable -- it jumps at $t=\bar{t}$ if and only if $p+0$ jumps at $t=\bar{t}--$ will be important when we come to consider the specification of the boundary conditions of this model -- our preferred model.

It is casily checked that the following relation holds for $\pi$

$$
\pi(t)=\pi\left(t^{-}\right)+\xi\left[p(t)-p\left(t^{-}\right)+\theta(t)-\theta\left(t^{-}\right)\right]
$$

where $\pi\left(t^{-}\right)=\lim _{\tau \rightarrow t} \pi(\tau)$ etc.

$\tau<t$

The jump in $\pi$ is $\xi$ times the sum of the jumps in $\mathrm{p}$ and $\theta$. Rewriting (24) in terms of the state variables we get

$$
\begin{aligned}
\pi(t)-\pi\left(t^{-}\right)= & \xi\left[(1-\alpha)\left(c(t)-c\left(t^{-}\right)\right)+\theta(t)-\theta\left(t^{-}\right)\right. \\
& \left.+l(t)-l\left(t^{-}\right)-\left(m(t)-m\left(t^{-}\right)\right)\right]
\end{aligned}
$$

If there are no level jumps in $m$ this becomes

$\left(24^{\prime \prime}\right) \pi(t)-\pi\left(t^{-}\right)=\xi\left((1-\alpha)\left(c(t)-c\left(t^{-}\right)\right)+0(t)-\theta\left(t^{-}\right)\right)$

For convenience we reproduce the complete model (to be used in Section 4) below. 


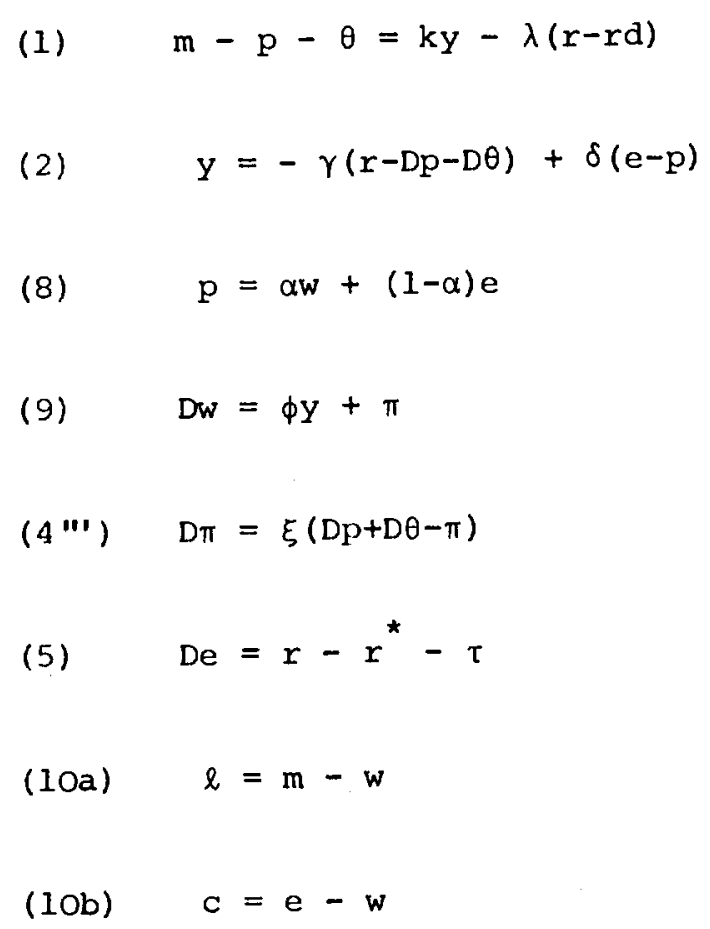

Its state-space representation is given in equations (25) and (26).

(25)

$$
\begin{gathered}
{\left[\begin{array}{l}
D l \\
D \pi \\
D C
\end{array}\right]=\Delta^{-1}\left[\begin{array}{lll}
\phi \alpha \gamma & \lambda+\alpha \gamma k & \phi \alpha(\lambda \delta-\gamma(1-\alpha)) \\
\xi(1-\alpha(1+\gamma \phi)) & \xi \lambda(1+\alpha(1+\gamma \phi)) & \xi[\alpha \phi(\gamma(1-\alpha)-\alpha \delta \lambda)-(1-\alpha)(1-\alpha(1-\delta k))] \\
1 & \lambda & \alpha \delta(\phi \lambda-k)-(1-\alpha)
\end{array}\right]\left[\begin{array}{l}
\ell \\
\pi
\end{array}\right]} \\
+\Delta^{-1}\left[\begin{array}{llll}
\Delta & -\phi \lambda \gamma(1-\alpha) & -\phi \alpha \gamma & -\phi \alpha \gamma \lambda \\
0 & \xi(1-\alpha)(\lambda+\gamma k) & -\xi(1-\alpha(1+\gamma \phi)) & -\xi \lambda(1-\alpha(1+\gamma \phi)) \\
0 & \lambda+\gamma(k-\phi \lambda) & -1 & -\lambda
\end{array}\right]\left[\begin{array}{c}
D^{-} \\
r^{*}+\tau \\
\theta \\
r_{d}
\end{array}\right]
\end{gathered}
$$

where $\Delta=\alpha \gamma(\phi \lambda-k)-\lambda<0$. 
(26) $\left[\begin{array}{l}r \\ y \\ D w \\ D p \\ D e\end{array}\right]=\Delta^{-1}\left[\begin{array}{lll}1-\alpha \gamma \phi & -k \alpha \gamma & -[k \alpha \delta+(1-\alpha \gamma \phi)(1-\alpha)] \\ -\alpha \gamma & -\alpha \lambda \gamma & -\alpha(\lambda \delta-\gamma(1-\alpha)) \\ -\alpha \gamma \phi & -(\lambda+\alpha \gamma k) & -\alpha \phi(\lambda \delta-\gamma(1-\alpha)) \\ 1-\alpha(1+\gamma \phi) & -\alpha(\lambda+\gamma k) & \alpha \phi(\gamma(1-\alpha)-\alpha \delta \lambda)-(1-\alpha)(1-\alpha(1-\delta k)) \\ 1-\alpha \gamma \phi & -k \alpha \gamma & -[k \alpha \delta+(1-\alpha \gamma \phi)(1-\alpha)]\end{array}\right]\left[\begin{array}{l}\ell \\ \pi \\ c\end{array}\right]$ $+\Delta^{-1}\left[\begin{array}{llll}0 & k \gamma(1-\alpha) & -(1-\alpha \gamma \phi) & -(1-\alpha \gamma \phi) \lambda \\ 0 & \lambda \gamma(1-\alpha) & \alpha \gamma & \alpha \gamma \lambda \\ 0 & \phi \lambda \gamma(1-\alpha) & \phi \alpha \gamma & \phi \alpha \gamma \lambda \\ 0 & (1-\alpha)(\lambda+k \gamma) & -(1-\alpha(1+\gamma \phi)) & -\lambda(1-\alpha(1+\gamma \phi)) \\ 0 & \lambda+\gamma(k-\alpha \lambda \phi) & -(1-\alpha \gamma \phi) & -\lambda(1-\alpha \gamma \phi)\end{array}\right]\left[\begin{array}{c}1 m \\ r^{*}+\tau \\ \theta \\ r_{d}\end{array}\right]$

We now turn to a more detailed study of the behaviour of the model of equations (25) and (26) in section 4 . 
4. The Real Exchange Rate and the Output Cost of Monetary Disinflation in a Model with Sluggish "Core" Inflation

In this Section we solve the model of equations (25) and (26) for the time paths of selected variables, using a particular set of "plausible" parameter values. The numerical example is designed to focus on the role of the real and nominal exchange rate in monetary disinflation. Two common channels of the monetary transmission mechanism are intentionally closed off. Thus "core" inflation in the labour market is backward looking (although $\pi$ will jump i.f.f. e jumps) and in addition, it is assumed that aggregate demand is interest inelastic: the IS curve is vertical. The real exchange rate continues to function as an effective channel of monetary policy, which is successful in bringing down steady-state inflation. We refer to this as policy $\mathrm{A}$.

We examine the mechanism through which inflation is reduced and calculate the costs in terms of lost output, incurred in the process. We also examine an alternative policy, referred to as policy $B$, which reduces the long run rate of inflation by the same extent without varying the real exchange rate, but following the same path of output. We note that these policies differ in their effects on the price level, even in the long run. In the short run, the recession induced by an overvalued exchange rate will show a sharper fall in the rate of inflation than the recession of equal magnitude induced by the alternative policy that keeps the real exchange rate constant. In the former case, there will also be an immediate fall in the price level, which is absent in the latter. Since the long-run real exchange rate is independent of the rate of monetary growth, the initial jump decline in $c=e-w$ under policy $A$ will be followed by a gradual increase in $e-w$ back to its initial level. On balance, during the adjustment process, De exceeds Dw. While $e-w$ is unchanged in the long-run, the new steady state paths of both $e$ and $w$ under $A$ lie below the initial steady state paths and are 
also lower relative to the path of the nominal money stock, since the lower steady state rate of inflation is associated with a higher stock of real money balances. It is possible (but not necessary) for $e$ to overshoot its new steady state path. I0/ In that case De will not only exceed Dw on balance during the adjustment process, it will also on balance exceed the new, lower, rate of monetary growth. (See Buiter and Miller [1981]). The alternative policy has the same real long-run equilibrium, including the same stock of real money balances but its long-run price level path lies above the price level path of policyA. Its endogenously determined long-run nominal money stock path also lies above the exogenously determined nominal money stock path of policyA.

We noted that under A on balance after the initial jump appreciation, De > Dw while with the alternative policy of model B, De $\mathbf{a}$ Dw . This does not mean that De will typically be larger with policy A than with B because the levels of the new steady state paths of $e$ and $w$ are lower in the former than in the latter.

another

We also briefly consider / policy designed to attain the same reduction in the rate of inflation as A, but without any loss of output. This policy involves a cut in indirect taxes and (in general) a change in the level of the nominal stock of money.

As long as $w$ is predetermined, the output cost of achieving a given reduction in the steady state rate of inflation (defined as the cumulative net amount of excess capacity) is entirely independent of the exchange rate. While it may be possible to bring forward the anti-inflationary gains, it is not possible to reduce the net output cost of bringing down inflation by engineering an early appreciation of the real exchange rate. 


\section{Parameter Values}

To illustrate the operation of the model we consider the results of choosing particular values for the parameters as follows:

$$
\lambda=2, k=1, \alpha=\frac{3}{4}, \phi=\xi=\delta=\frac{1}{2} \text {. }
$$

With these values substituted into equation (2.5) the system becomes

$$
\left[\begin{array}{c}
D \ell \\
D \pi \\
D C
\end{array}\right]=\left[\begin{array}{ccc}
0 & -1 & -3 / 16 \\
-1 / 16 & -1 / 8 & 7 / 64 \\
-1 / 2 & -1 & 1 / 8
\end{array}\right]+\left[\begin{array}{l}
l \\
\pi \\
c
\end{array}\right]+\left[\begin{array}{l}
\mu \\
0 \\
r *
\end{array}\right]
$$

The characteristic equation is $\rho^{3}-\frac{p}{16}-\frac{3}{64}=0$ and the determinant is $3 / 64$, sce Appendi.y.

The roots are 0.418 and $-0.209 \pm 0.2618 i$ and the row eigenvector associated with the positive roots $\hat{\rho}$ is found to be

$$
\left[\hat{v}_{1}, \hat{v}_{2},-1\right]=[1.271,-0.499,-1]
$$

The impact effects of an unanticipated change in monetary growth (du) (see Appendix)

Using these values for $\hat{\rho}_{,} \hat{v}_{1}, \hat{v}_{2}$ we find/the initial jump in competitiveness is $\mathrm{dc}=2.8624 \mathrm{~d} \mu$, that is, the initial percentage change in competitiveness will be just under three times the percentage change in monetary growth announced by the monetary authorities. The immediate effect that this has on the "core" rate of inflation is

$$
\mathrm{d} \pi=\xi(1-\alpha) \mathrm{dc}=\frac{\mathrm{dc}}{8}=0.36 \mathrm{~d} \mu
$$


Given the simple structure of the model, the change in competitiveness will be associated with an immediate change in output

$$
d y=\delta a d c=\frac{3}{8} d c * 1.1 d \mu
$$

so output will change by roughly the change in the rate of monetary growth.

The rate of wage settlements will jump on impact as a result of both the shift in $\pi$ and of the recession as follows:

$$
\mathrm{d}(D w)=\phi d y+d \pi=(\phi \delta \alpha+\xi(1-\alpha)) \mathrm{dc}=\frac{5 \mathrm{dc}}{16} \approx 0.3 \mathrm{~d} \mu
$$

\section{The long run equilibrium}

In a system which is super-neutral, one would not expect a change in monetary growth to affect the equilibrium real interest rate or the real exchange rate, though nominal interest rates will reflect the monetary slowdown. By setting the left hand side of equation (27) at zero and differentiating with respect to $\mu$, we can confirm that a change in $\mu$ has no long run effect on $c$, but changes $\pi$ one-for-one. As the equilibrium nominal rate of interest will also move in line with $\mu$, the impact on real balances in the long run is $-\lambda d \mu$

\section{The dynamic behaviour of the system}

The dynamic behaviour of the variables in the system is summarised in Table 1. In the first column of panel (a) are shown the "starting values" for $\ell, \pi$ and $c$ discussed above, measured as deviations from their 
new equilibrium values after a one point slowdown in monetary growth at $t=0$. (All variables are scaled by 100 so a one point slowdown in monetary growth will appear as $\mathrm{d} \mu=-1.0)$. The second column shows Dl, DT, DC at time zero calculated fromequation/ and from the first column.

These starting values are chosen so as to place the system on the two dimensional stable manifold, on which the stable path of $\ell, \pi$, and $c$ can be described by

$$
x(t)=e^{\rho t}\left(B_{1} \cos \omega t+B_{2} \sin \omega t\right)=B e^{\rho t} \cos (\omega t-\varepsilon)
$$

where the values for $\mathrm{B}_{1}, \mathrm{~B}_{2}$, Band $\varepsilon$ are calculated from the initial conditions in the first two columns.

The same parameters, calculated in the same manner, are shown for $y, D w, D c$ and $D p$ in the second panel of Table 1 . These variables are also measured as deviations from their new equilibrium values. For output, $y$, this is zero, by construction, but for wage and price inflation $(D p$ and $D w)$ the new steady state will correspond to the new rate of monetary growth $(\overline{\bar{\mu}})$. For convenience, in what follows, we will assume that the newly chosen rate of monetary growth is zero, so that there is no inflation in the new equilibrium.

A check on the calculations contained in the table, and some indication of how the policy works, is obtained by integrating the paths shown there for $D w$ and $D p$. The formulal/ which gives the required integral is

$$
\int_{0}^{\infty} x(t) d t=\frac{-\rho B_{1}+\omega B_{2}}{\rho^{2}+\omega^{2}}
$$

where $B_{1}$ and $B_{2}$ are shown in the body of the table and the values for $\rho$ and $\omega$ are given in Note 2 to the table. Applying this we find: 
Table 1

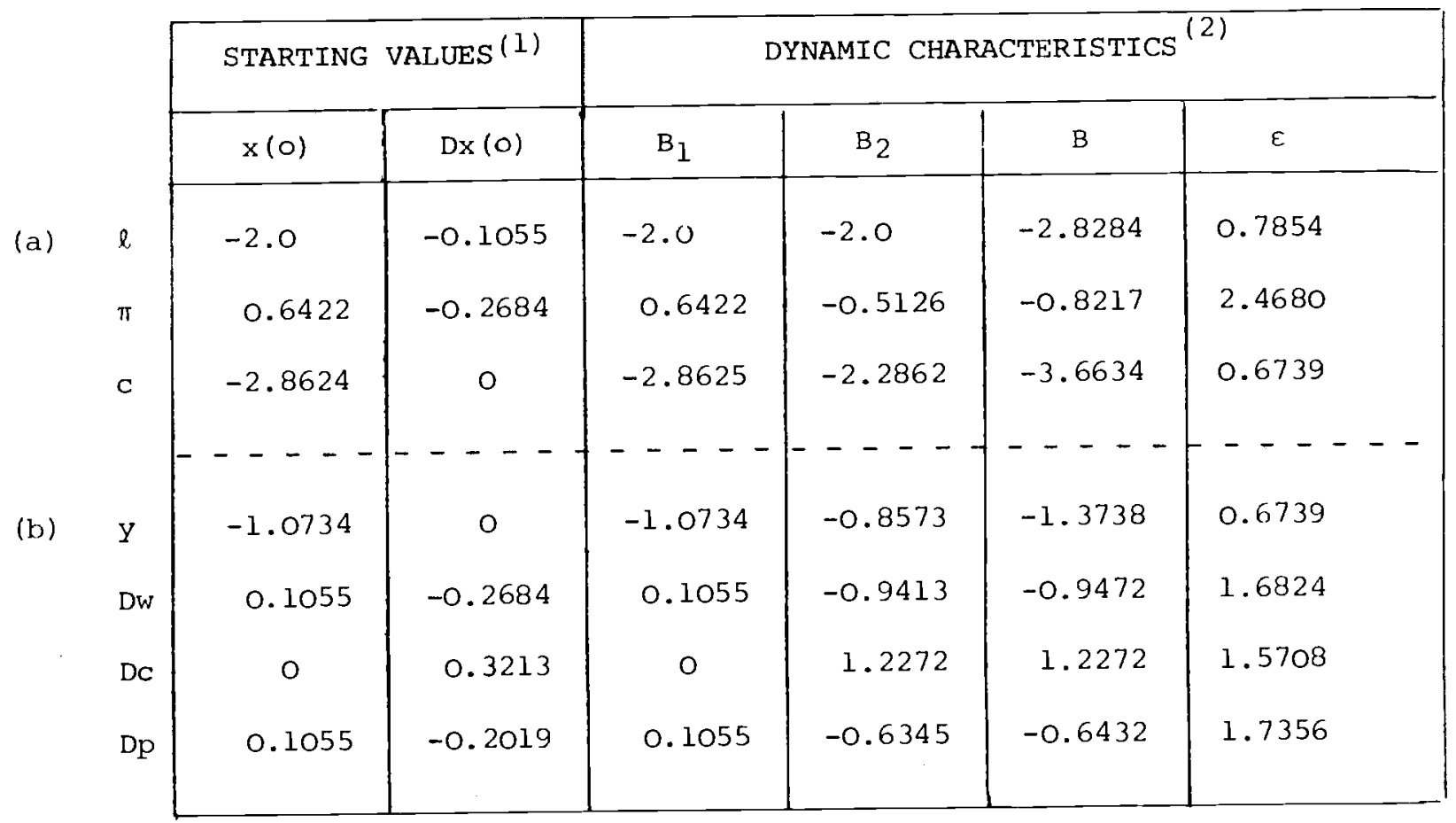

ALTERNATIVE POLICY ${ }^{3}$

\begin{tabular}{|c|c|c|c|c|c|c|}
\hline (c) $Y$ & -1.0734 & 0 & -1.0734 & -0.8573 & -1.3738 & 0.6739 \\
\hline & 0.4633 & -0.2684 & 0.4633 & -0.6553 & -0.8026 & 2.1862 \\
\hline
\end{tabular}

NOTES

(1) See Text for derivation of $x(0)$ for $\ell, \pi, c ; \quad D x(0)$ can be obtained by multiplying matrix shown in (27) into $x(0)$.

(2) Damping factor $p=-0.2090$, frequency $\omega=0.2618$

(3) For which $\pi(0)=1.0$, and $y$ follows same path as above. (See text) 


$$
\int_{0}^{\infty} D w(t) d t=-2.0 \quad \text { and } \quad \int_{0}^{\infty} D p(t) d t=-1.2843
$$

The discrepancy is accounted for by the fact that the price level shows an instantaneous discrete fall at time zero, which is not picked up in the integration. The fall will be simply $(1-\alpha)$ dc, where dc measures the initial impact of the monetary policy for competitiveness. The initial loss of competitiveness is -2.864 (see the first entry in the third row of the table), and $1-\alpha$ is 0.25 , which provides a figure of -0.7156 for the initial fall in the price level. Together with the integral reported above, this gives a total of -2.0 for the long run effect on the price level. Thus the real wage is unchanged in the long run, as one would expect from a model which is "super neutral". (The 2\% fall in the price level is required to increase real balances to satisfy the higher demand for liquidity at the lower nominal interest prevailing when prices are stable).

The cyclical path towards this long run value is sketched in Figure 11. In the top panel of Figure 11, by choice of units, both the price level and the money stock can be represented by the same line, $C_{B}$, until the time $t=0$ of the monetary slowdown. The money stock levels off at point $B$, and the price level jumps down (because of the jump-appreciation of e) and then rises for a while as shown by the path labelled $A$ A.

In the lower panel of Figure 11 , the paths after t=o for monetary growth (the/ and the rate of price inflation $\left(n \mu_{i}\right)$ are shown. It is evident from the fact that the initial rate is only a little above zero that this policy has a prompt effect upon inflation. This effect is due to two factors; the immediate fall in core inflation (by about $\frac{1}{3}$ from 1.0 to 0.6422 , see "l.able 1, column 1, row 2) and the recession in output (of just over 1.0, see Table 1, column 1, row 4). 


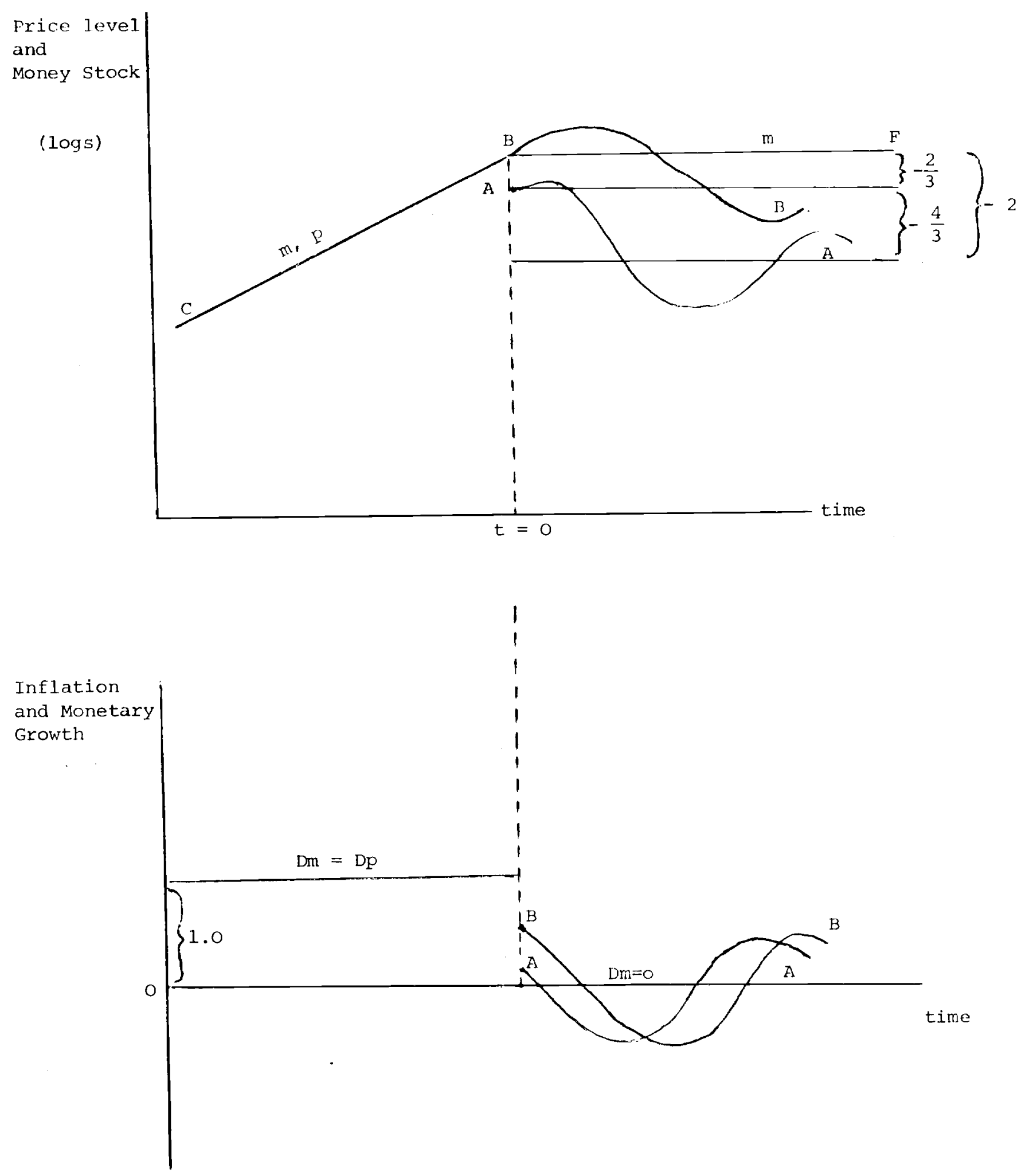

Figure 11 Money and Prices 
This rapid fall in inflation might lead one to be optimistic about the costs of eliminating inflation as measured by the size and duration of the recession. Butif we measure the output costs of checking inflation simply by the unweighted integral of $y$ (which means that some of the recession is cancelled out by subsequent boom as output cycles towards equilibrium) the following expression for the cumulative net loss of output can be obtained:

$$
\int_{0}^{\infty} y(t) d t=\frac{\overline{\bar{\mu}}-\bar{\mu}}{\xi \phi}
$$

with $\overline{\bar{\mu}}-\bar{\mu}=-1.0$ and $\xi \phi=.25$, the cumulative net output cost required to bring down the steady-state inflation rate by 1 percentage point is four "puint years" loss of output. $12 /$

Our model ignores possible benefits from bringing down inflation slowly due to non-linearities in the Phillips curve which might cause two years with $5 \%$ excess capacity to have a stronger counterinflationary effect than 1 year with 108 excess capacity. The evidence on this is, however, by no means clear.

We now consider alternative policies which specifically avoid any fluctuations in competitiveness. We see how they compare with what we have just seen for the policy $A \quad . \quad$ in terms of the speed with which inflation is reduced and the cost in terms of lost output.

\section{Alternative policies}

In order to see how much the initial loss of competitiveness contributes to the speed with which inflation is reduced and to cutting the cost of reducing inflation we consider alternative policies which keep competitiveness constant at its long-run equilibrium value throughout. If competitiveness 
is thus kept constant and $\mathrm{c}=\mathrm{e}-\mathrm{w}=0$, the price level and the wage rate will move together, as can be seen from equation (8). As a consequence the inflation process in the model reduces to the familiar augmented Phillips curve commonly used to characterize closed economies. We get (23) $\quad D p=\phi y+\pi$ (4"') $\mathrm{D} \pi=\xi(\mathrm{Dp}-\pi)$

The stabilization of the real exchange rate precludes both the discrete adjustment to the core rate of inflation $\pi$, which was a feature of the previous policy, as well as any discrete jumps in the price level. Both $\pi$ and $p$ are predetermined. Given the initial level of core inflation $\pi(0)=\bar{\mu}=1.0$, the initial value of the price level $p(0)$ and a path for real output, equations (28) and (4"') will by themselves generate the entire path to be followed by the price level. Note that, by construction, money has become a complete "side-show". Two of the transmission mechanisms, the real balance effect and an interest rate effect in the goods market, have been ruled out from the start. Now that the real exchange rate is also kept constant, there is no feedback from money on real output. Since the model has the standard homogeneity properties, it will of course still be true that in the long run the rate of inflation equals the rate of growth of the money supply. As will become clear, however, the truism that "inflation is always and everywhere a monetary phenomenon" should in the current example be turned around: money here is an inflation phenomenon.

The first alternative policy ( $c a l l e d B$ ) takes the path of output to be precisely the same as that generated by the monetary contraction just described with policy A.This can be achieved e.g. by adding a fiscal instrument $g$ to the Is curve so that 


$$
y=\delta a c+n g \quad n>0
$$

With c kept constant at 0 , we can duplicate policy A's real output path by making $n g$ follow the exact path of $\delta \alpha c$ under $A$. The real exchange rate could e.g. be stabilized by adopting the exchange rate management rule that $D e=D w$. This then implies of course that $D e=D p$. with the exchange rate thus managed, the nominal money stock is endogenously determined. When $D e=D w=D p$, the nominal interest rate is given by $r=r^{*}+D e=r^{*}+D p$. The LM equation (1) then becomes

$$
m=p-\lambda\left(r^{*}+D p\right)+k y=p-\lambda r^{*}+(k-\lambda \phi) y-\lambda \pi
$$

With $p$ and $\pi$ predetermined and $y$ determined by (29) with $c=0$, equation (30) determines the nominal money stock. Other ways of stabilizing the real exchange rate such as a variable tax on capital inflows (subsidy on outflows) can be thought of. In the present example the inflation generated by equations $(28),(4 " ')$ and $(29)$ (with $c=0$ ) is the dog wagging the money supply tail through equation (30). Given equations (a) and (4"') it will of cours' always be the case that the path of inflation is determined once a path for output is specified. If other transmission mechanisms of monetary policy, such as an interest rate effect and a real balance effect in the output market, are included in the model, however, it is less straightforward (although possible) to specify an output path without reference to the money supply.

The results of the alternative policy for inflation are shown in the bottom row of Table 1. Inflation starts at a significantly higher level than before with/ A because the starting value for core inflation $\pi$ is now $\bar{\mu}=1.0$. The path followed by inflation has the same damping factor $\rho$ and frequency $\omega$ as the output path but the amplitude is smaller and the inflation cycle leads the output cycle. The rate of inflation will, as 
before, be reduced to zero at a net cost of 4 point-years of output. The price level towards which the system converges under the alternative policy is, however, higher than the long-run price level of policyA. This can be seen from the coefficients in Table 1 . While $\int_{0}^{\infty} D p_{A}(t) d t=-2$ for Model $A$, as we have already discussed, integrating the path for inflation under Model B yields a smaller fall, as follows

$$
\int_{0}^{\infty} D P_{B}(t) d t=\frac{-\rho 0.4633-0.6553 \omega}{\rho^{2}+\omega^{2}}=-\frac{2}{3} \text {. }
$$

These results are illustrated in Figure 11 where the path followed by the price level and the rate of inflation under policy $B$ are plotted alongside those already described for policyA. In the top panel the price level under the alternative policy proceeds from point B without any "jump" along a path which cycles around a steady state level which is $\frac{2}{3}$ of a point below the line BF showing the level of the money stock, which is $\frac{4}{3}$ of a point above the corresponding steady state shown for policy A.

In the bottom panel the rate of inflation is shown starting at point is and cycling towards zero along the path $\mathrm{BB}$. Thus inflation starts at a higher level under the alternative policy than under the floating exchange rate case. The determination of those "starting values" and the subsequent comparison of inflation can be seen from Figure $12 . \quad$ There, labelled $\mathrm{SRPC}_{B}$, is the "ghort-run Phillips curve" which determines initial inflation under policy $B$ where $\pi_{B}(0)=\vec{\mu}$. This value of $\pi$ determines the intercept of $S_{R P C}$, and the value of $y(0)$ determines the value of inflation shown as $\mathrm{DP}_{B}(0)$. From this point inflation and output cycle towards the origin as shown: by the path labelled $\mathrm{BB}$. 
By contrast the relationship determining inflation under policy A, (after the initial jump at time zero),

$$
D P_{A}(0)=\phi y(0)+\pi_{A}(0)+\frac{(1-\alpha)}{\alpha \delta} D y(0)=\phi Y(0)+\pi_{A}(0) \text { as } D Y(0)=0 \text {, }
$$

yields the Phillips curve shown as $S R P C C_{A}$ which has an intercept of $\pi_{A}(0)$ which is lower than $\pi_{B}(0)$ because of the jump induced by the revaluation of the currency at the inception of the monetary slowdown under floating rates. Thereafter inflation falls away following the path shown as AA.

The gap between the two paths in the top panel, Dé , can be plotted against time. Its dynamic characteristics (after the jump in $p_{A}$ ' are obtained from Table 1 where

$$
\begin{aligned}
D \vec{p} \equiv D p_{A}-D p_{B} & =e^{\rho t}(-0.3578 \cos \omega t+0.0208 \sin \omega t) \\
& =0.3583 e^{\rho t} \cos (\omega t-3.0855)
\end{aligned}
$$

The path of Dp is therefore sinusoidal and its integral is - 0.6183 , which together with the initial jump in the price level, gives the figure of $-\frac{4}{3}$ as the long-run difference in the price level resulting from the two policies.

What is apparent from the above is that the policy of fighting inflation by cycles in output and in the real exchange rate (with an initial recession associated with an overvalued exchange rate) does not lead to any change in long run inflation, compared to the same output cycle and a stable real exchange rate. The loss of competitiveness does however reduce inflation more quickly early on, as shown in Figure 12; the early lead established by this policy over the alternative is whittled away later when competitiveness is regained in the boom, but we are left with the conclusions that inflation is brought down more quickly with policy $A$, as shown by the dotted line in Fiqure 12.) (Inflation under the alternative policy is shown by the solid 1ine.) 


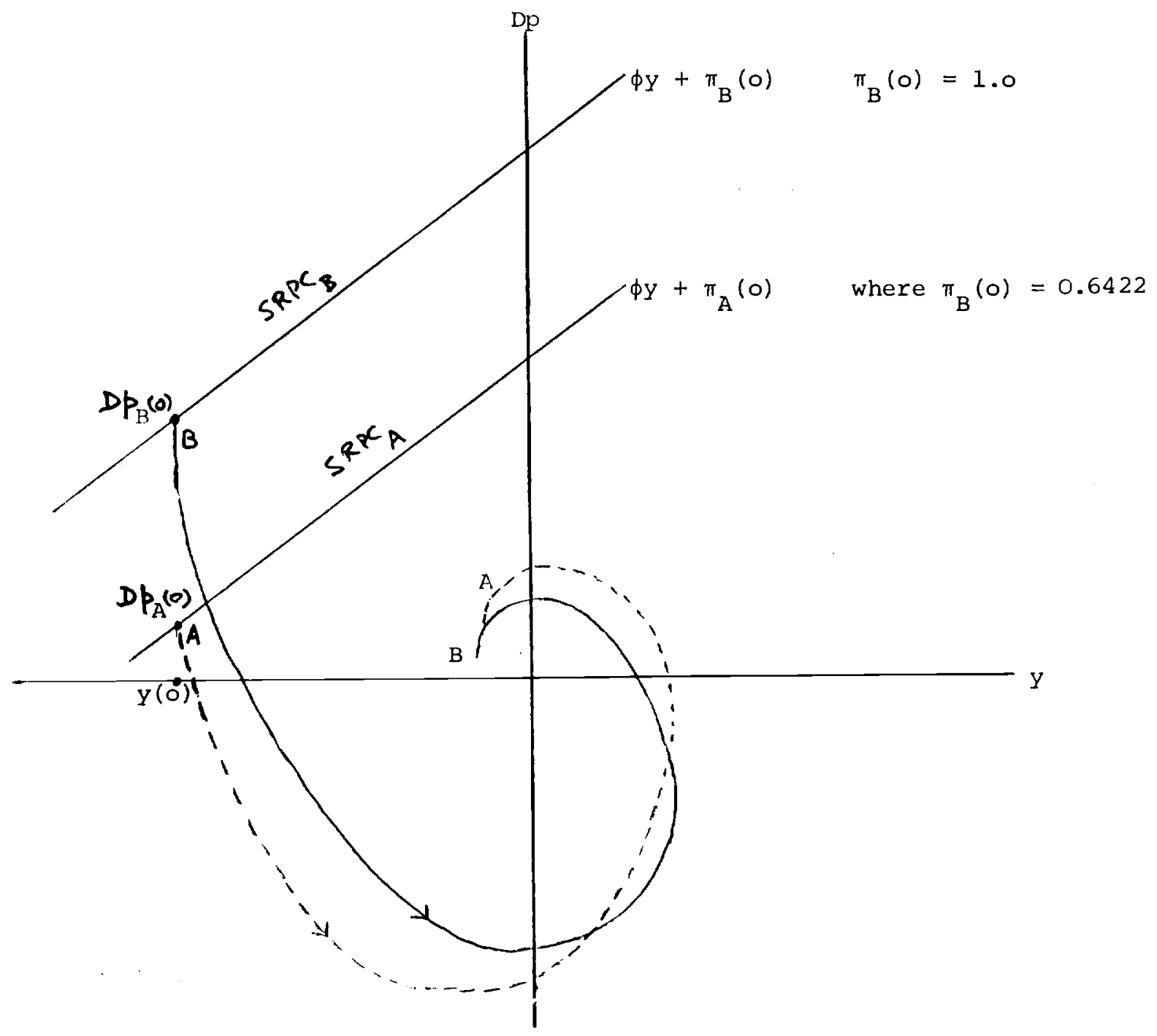

Figure 1: Inflation under the two policies

The fluctuations of the real exchange rate can therefore be seen to have effects on inflation rot unlike those attributed to temporary incomes policies by those who argue that the latter hold down inflation in the short run, but have no effect on the inflation rate in the long run. If that is true, then a temporary bout of incomes policy would change only the long run price level without changing the long run growth of prices, which is what we have found to be characteristic of the policy of permitting the real exchange rate to vary. 
"Efficient disinflationary policies".

Once we permit changes in the indirect tax rate, $\theta$, we have a way of costlessly reducing inflation. Consider the money demand function and the wage equation:

$$
\begin{aligned}
& m-p-\theta=-\lambda r+k y \\
& D w=\phi y+\pi
\end{aligned}
$$

Given a reduction in the rate of monetary growth by $d \mu=\overline{\bar{\mu}}-\bar{\mu}$, we can easily calculate the change in $\theta$ required to jump $\pi$ to its new long-run equilibrium value, $\overline{\bar{\mu}}$. Holding $p$ constant, equation (24) shows that $d \pi(t)=\xi d \theta(t)$. The required change in $\theta$ is therefore given by

$$
\mathrm{d} \theta=\xi^{-1} \mathrm{~d} \pi=\xi^{-1} \mathrm{~d} \mu
$$

From the money market equilibrium condition we obtain that, since the long run interest rate changes in line with $\mu$,

$$
d(m-p-\theta)=-\lambda d r=-\lambda d \mu
$$

Holding $p$ constant this yields

$$
\mathrm{dm}-\mathrm{d} \theta=-\lambda \mathrm{d} \mu
$$

or

$$
d m=\left(-\lambda+\xi^{-1}\right) d \mu
$$

Therefore a change in the rate of monetary growth by $d \mu$, accompanied by a change in indirect taxes by $\xi^{-1} \mathrm{~d} \mu$ and a change in the level of the nominal money stock of $\left(-\lambda+\xi^{-1}\right) d \mu$ will immediately move the system to the new steady-state equilibrium with the lower rate of inflation. output and the real exchange rate are unaffected. With our choice of parameter values $(\lambda=2$ and $\xi=.5) \cdot d \theta=2 d \mu$ and $d m=0$. 
The mechanism permitting the required reduction in inflation to be brought about without loss of output is the following. First, the cut in $\theta$ (in general together with the change in $\mathrm{m}$ ) permits the long-run change in the stock of real money balances to be brought about immediately without any need for a jump in nominal prices, including the exchange rate. Second, the cut in $\theta$ achieves the immediate change in the core rate of inflation to its new long-run value. The use of indirect taxes to facilitate the process of bringing down inflation has been advocated frequently by okun $[1978]$.

Alternatively, incomes policy can be used to jump $\pi$. If incomes policy can be identified with a once-and-for-all reduction in $\pi$, without any other "overwriting" of the behavioural equations of the model, then it will lower the cost of disinflation. If monetary policy changes or announcements themselves directly change $\pi$, as is the case in the model of section 2 , then disinflationary monetary policies will also be "efficient" in the sense we are using that term here.

\section{Conclusion}

After a summary of various approaches to the modelling of the inflationary process in an open economy with a floating exchange rate, we have studied the way in which a monetary slowdown might be expected to work in an economy where core inflation is sluggish, and adjusts to actual inflation with a significant mean lag. 
Despite such sluggishness we found that core inflation can be reduced quickly by jumps in the price level induced by jumps in the exchange rate. In the simple model used to focus on this particular aspect of the monetary transmission mechanism we found that, even without any direct real balance and real interest rate effects on aggregate demand, a monetary slowdown might nevertheless cut inflation promptly via its impact on the nominal and the real exchange rate. Indeed our numerical example has the property that the inflation rate responds immediately by almost the full extent of the monetary slowdown: Thus reduction of inflation follows, in our example, from the effects of announced monetary policy on the exchange rate. The appreciation of the exchange rate cuts the inflation rate in two ways, first by reducing core inflation and second by cutting the level of output. Both of these effects involve sharp changes in the real exchange rate.

Since the model is "super-neutral", however, such changes in the real exchange rate and in real output must ultimately be reversed. Pursuit of a constant growth rate of money generates a cyclical convergence for these variables. The net output costs associated with a steady state reduction in inflation are found to be given by a simple formula, $d \mu / \xi \phi$ where $d \mu$ shows the change in steady state inflation, $\phi$ is the slope of the short-run Phillips curve and $\xi$ measures the speed of adjustment of core inflation. Thus for $\xi=\phi=\frac{1}{2}$ the net output loss associated with reducing monetary growth and steady state inflation by $1 \%$ is 4 point years of GNP.

For comparison we considered an alternative where the real exchange was held constant but output was constrained to follow the same path as before. Such an alternative, whose net output loss is of course identical, was found to achieve the same effect on steady state inflation, but the path taken by inflation was different. The prompt anti-inflation success due to the loss of competitiveness being absent, inflation starts from a higher level under this alternative. The early lead achieved by the policy of "overvaluing" 
the currency is never entirely lost, so that the long run price level is lower than is true for the alternative policy.

In a super-neutral model, with core inflation modelled in the way we have, it turns out that any path for output which exibits a cummulative 4 point-year loss of output will (if $\xi \phi=\frac{1}{4}$ ) reduce steady state inflation by $1 \%$, irrespective of the path taken by the real exchange rate (provided it starts and finishes at the same level). Thus the freedom to vary the real exchange rate in order to reduce inflation does not succed in reducing the output costs of changing steady state inflation; it does however change the time path of inflation, relative to other policies which exhibit the same output jath.

While the numerical model makes no claim to being a realistic model of the U.K., we would point out that the sort of output costs associated with reductions in medium term inflation in Treasury evidence to the Treasury Committee suggested a figure of 4 point years of output for each 1 point off medium term inflation. A more detailed analysis of simulations on an earlier version of the Treasury model, when the slope of the Phillips curve was flatter and the mean lag of core inflation longer, showed even higher cost.s (see Miller [1979]).

In considering "efficient" disinflationary policies, we noted that a cut in indirect taxes could reduce the output costs of curing inflation by securing an immediate jump reduction in the price index at market prices and in the core rate of inflation. In our model a reduction in the rate of growth of money by $d \mu$ accompanied by a cut in indirect taxes of $\xi^{-1} d \mu$ will immediately and costlessly achieve a reduction in steady state inflation of $\mathrm{d} \mu$. (In general a change in the level of the money stock will also be required) . 
In the U.K., a one point cut in VAT is reckoned to cut the rate of indirect taxation by half a point. A 4 point reduction in VAT would therefore avoid the four point year of output loss otherwise associated with a point reduction in monetary growth. The present administration's decision to raise VAT by 8 points early in their term of office, at the same time that a programme of successive reductions in monetary growth was announced, would in our model increase the cost of bringing down inflation. In the short run however, the adverse consequences of the VAT increase on the price level are countered by the appreciation of the exchange rate.

Those who argue that incomes policies can secure a step reduction in core inflation, would of course advocate their use as a way of cutting the output costs of reducing inflation (see, for example, Tobin [1977]). We have not examined this case in detail in this paper. We have however, considered the possibility that announced monetary policy could immediately and directly reduce core inflation in just such a fashion. If announced monetary policy has this sort of direct expectational effect, then it will save output costs, just as a similarly successful incomes policy would. If, however, monetary targets only secure immediate effects on core inflation by a sudden loss of competitiveness, this will not constitute an "efficient" way of reducing inflation. 
Appendix:

Derivation of the initial conditions

First, we note that when aggregate demand is completely interest inelastic (i.e. $\gamma=0$ ), the term $\Delta$ in (25) and (26) becomes $-\lambda$ and, omitting $\theta$, $\tau$ and $r_{d}$ ' equation (25) simplifies to:

$(A 1)\left[\begin{array}{l}D \ell \\ D \pi \\ D C\end{array}\right]=\left[\begin{array}{ccc}0 & -1 & -\phi \delta \alpha \\ -\xi(1-\alpha) \lambda^{-1} & -\xi(1-\alpha) & \xi(1-\alpha) \lambda^{-1}(1-\alpha+k \delta \alpha)+\phi \delta \alpha^{2} \\ -\lambda^{-1} & -1 & \lambda^{-1}(1-\alpha+k \delta \alpha)-\phi \delta \alpha\end{array}\right]\left[\begin{array}{l}\ell \\ \pi \\ c\end{array}\right]+\left[\begin{array}{l}D m \\ 0 \\ r^{*}\end{array}\right]$

where the determinant of the coefficient matrix A in (27) is given by $\Omega=\xi \lambda^{-1} \delta \alpha>0$ and the characteristic equation, $f(\rho)=0$, where $\rho$ is a root, is

$$
\rho^{3}-\left[\left(\lambda^{-1}-\xi\right)(1-\alpha)+\left(k \lambda^{-1}-\phi\right) \delta \alpha\right] \rho^{2}
$$

$(2,3)$

$$
-\left[\left(\lambda^{-1}-\xi\right) \phi \delta \alpha+\xi(1-\alpha) \lambda^{-1}\right] \rho-\Omega=0 .
$$

As can be seen from the characteristic equation, $f(0)<0$ as $\Omega>0$, but $f(\rho)$ tends to infinity when $\rho$ tends to infinity; hence there exists one positive root, which is not surprising given the presence of the forward looking variable, $c$. The other two roots must be stable for the model to make sense. (For most plausible values of the parameters these other roots will turn out to be complex, as we see below).

The row eigenvector $v^{\prime}$ associated with any root must satisfy the condition that $v^{\prime}[\rho I-A]=8^{\prime}$ where $\mathbf{z}^{\prime}$ denotes the zero vector. Normalizing the eigenvector appropriately, this means 
(A3) $\left[\begin{array}{lll}v_{1} & v_{2} & -1\end{array}\right]\left[\begin{array}{ccc}\rho & 1 & -a_{13} \\ \xi(1-\alpha) \lambda^{-1} & \rho+\xi(1-\alpha) & -a_{23} \\ \lambda^{-1} & 1 & \rho-a_{33}\end{array}\right]=\left[\begin{array}{lll}0 & 0 & 0\end{array}\right]$

where the last column is not given in full for simplicity. This implies

$$
\begin{aligned}
& v_{1}=1-v_{2}(\rho+\xi(1-\alpha)) \\
& v_{2}=\frac{1}{\xi(1-\alpha)-\rho^{2}\left(\lambda^{-1}-\rho\right)^{-1}}
\end{aligned}
$$

To ensure stability, the path to be followed by the system must not depend on the eigenvector associated with the positive (unstable) root. Avinash Dixit [1980] has shown that for a previously unanticipated,immediately implemented shock this can be achieved by ensuring that the product of this eigenvector with the initial values of the variables (measured as deviations from the new long-run equilibrium) equals zero, i.e.

$$
\hat{\mathrm{v}}_{1}(l(0)-\overline{\bar{l}})+\hat{\mathrm{v}}_{2}(h(0)-\overline{\overline{\mathrm{h}}})-(c(0)-\overline{\bar{c}})=0
$$

$\overline{\bar{\ell}}, \overline{\bar{h}}$ and $\overline{\bar{c}}$ are the new long-run equilibrium values of $\ell, h$ and $c$ and $\hat{v}_{1}$ and $\hat{v}_{2}$ are elements associated with the unstable root.

Let $D m \equiv \mu$. The terms measuring initial disequilibrium following an unanticipated change in $\mu$, denoted $d \mu$, can be evaluated as follows:

\footnotetext{
$\ell(0)-\overline{\bar{l}}=\lambda \mathrm{d} \mu$

(A4) $\pi(0)-\overline{\bar{\pi}}=\pi(0)-\overline{\bar{\mu}}$, where $\overline{\bar{\mu}}$ denotes the new value of $\mu$. $c(0)-\overline{\bar{c}}=d c$, the jump in competitiveness.
} 
From equation (24") we know that

$$
\mathrm{d} \pi=\xi(1-\alpha) \mathrm{dc}
$$

and so the initial disequilibrium in $\pi$ becomes

$$
\pi(0)-\pi=\xi(1-\alpha) d c-d \mu .
$$

Hence equation (29) can be rewritten as

$$
\hat{\mathrm{v}}_{1} \lambda \mathrm{d} \mu+\hat{\mathrm{v}}_{2}(\xi(1-\alpha) \mathrm{dc}-\mathrm{d} \mu)-\mathrm{dc}=0
$$

and so the initial change in competitiveness found to be

$$
d c=\frac{\hat{v}_{1} \lambda-\hat{v}_{2}}{1-\hat{v}_{2} \xi(1-\alpha)} d \mu
$$




\section{FOOTNOTES}

1) For simplicity, the term $D \theta$ in equation (2) has been ignored. We consider it in Section 4

2) The equilibrium is a saddlepoint if the state matrix has one stable and one unstable characteristic root. A necessary and sufficient condition for this is that the determinant of the state matrix be negative.

3/ It is casily checked that $r$ declines less than DI . Note also that we can use (2) and (5) to obtain: $y=-\gamma D C+\delta c-\gamma\left(r^{*}+\tau\right)$. Immediately following the unanticipated reduction in $\mathrm{Dm}, \mathrm{C}$ is lower and DC becomes positive. This causes $y$ to fall.

4) We assume that the policy announcement was unanticipated and credible -- perhaps a doubtful assumption.

5) The Thatcher government's $8 \%$ increase in VAT has been estimated to be equivalent to a 4 percentage point increase in the average rate of indirect taxation, $\theta$.

6) A more general approach is the following. Let $p_{H}$ be the price of domestically produced goods. It is a weighted average of unit labour costs, $w$, and unit imported intermediate input costs: $e+p^{\star} I$, i.e. (12') $\mathrm{p}_{\mathrm{H}}=\beta_{1} w+\left(1-\beta_{1}\right)\left(e+\mathrm{p}^{*}\right) \quad 0 \leqslant \beta_{1} \leqslant 1$. The domestic price level or c.p.i. is a weighted average of the price of domestically produced goods and the price of imported final goods $e+p^{\star} F$, i.e. (12") $\mathrm{p}=\beta_{2} \mathrm{p}_{\mathrm{H}}+\left(1-\beta_{2}\right)\left(e+\mathrm{p}^{\star} \mathrm{F}\right) \quad 0 \leqslant \beta_{2} \leqslant 1$. For our purposes not much is lost by using the simpler formulation in (12). An alternative interpretation in terms of traded and untraded goods is also possible. 
7/ These issues are discussed for the fixed exchange rate case in Buiter [1978, 1979].

8) Since the adjustment path of output is monotonic in all our examples, $y$ does not change sign during the transition. The net output loss therefore also equals the gross output loss.

9/ The $D \theta$ term is again omitted. It will be discussed in section 4.

10/ The slope of this path equals the new rate of monetary growth.

11/ Kindly provided by Peter Burridge and Avinash Dixit.

12f As a measure of economic waste, $\int_{0}^{\infty} y(t) d t$ is only really useful if $y(t)$ does not change sign on the interval $\mid 0, \infty)$. zero net output loss is consistent with periods of prolonged and large excess supply followed by periods of prolonged and large excess demand. A more appropriate index of economic waste might be

$\int^{\infty}|y(t)| d t$, which penalizes all deviations of output from capacity output in the same way.

13/ Okun [1978].

14) This would happen in a flexible money wage model if the VAT increase is matched by a reduction in direct taxes or, if it is not thus matched, if the supply of labour is completely inelastic with respect to the after-tax real wage. 
REFERENCES

Buiter, W. H. [1978] "Short-Run and long-run Effects of External Disturbances under a Floating Exchange Rate", Economica, 45, pp $251-272$.

Buiter, W. H. [1979] "Unemployment - Inflation Trade-Offs with Rational Expectations in An Open Economy", Journal of Economic Dynamics and Control, 1, June 1979, pp 117-141.

Buiter, Willem H. and Marcus Miller [198]] "Monetary policy and International competitiveness", forthcoming in Oxford Economic Papers, September.

Dixit, Avinash [1980] "A Solution Technique for Rational Expectations Models with Applications to Exchange Rate and Interest Rate Determination", Mimeo, University of Warwick, November.

Dornbusch, Rudiger [1976] "Exchange Rate Dynamics", Journal of Political Economy, 84, December, pp. 1161-1176.

Frenkel, J. [1980] "The Collapse of purchasing Power Parities in the 1970's", Working Paper, University of Chicago, Chicago, Ill.

Isard, P. [1977] "How Far Can we Push the Law of one Price", American Economic Review, 67, pp. 942-9.

Kravis, I. and R. Lipsey [1978] "Price Behaviour in the Light of Balance of Payment Theories", Journal of International Economics, 8 pp. 193-247.

Liviatan, N. [1980] "Anti-inflationary Monetary Policy and the Capital Import Tax", Warwick Economic Research Paper, No. 171.

Miller, M. [1979] "The Unemployment Costs of Curing Steady State Inflation", Mimeo, University of Warwick.

Minford, P [1980] "A Rational Expectations Model of the U.K. under Fixed and Floating Exchange Rates" in K. Brunner and A. Meltzer eds. The state of Macroeconomics, Carnegie, Rochester Conference Series on Public policy.

Okun, Arthur M. [1978] "Efficient Disinflationary Policy", American Economic Review, 68, May, pp. 353-7.

Sargan, J. D. [1980] "A Model of Wage-Price Inflation", Review of Economic Studies, 47, January, pp. 97-112.

Tobin, James [1977] "How Dead is Keynes?" Economic Enquiry, 15, October, pp. 459-68. 
</ref_section> 